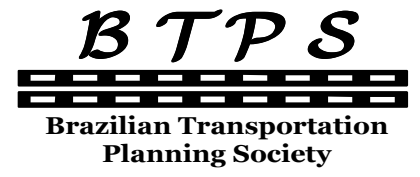

Planning Society
Journal of Transport Literature

Vol. 8, n. 3, pp. 107-138, Jul. 2014

Research Directory
JTLIRELIT www.transport-literature.org
ISSN 2238-1031

\title{
Padrão de viagens geradas por instituições de ensino superior privadas da cidade de Uberlândia
}

[Standard of trips generated by private universities of the city of Uberlândia, Brazil]

\author{
Ana Flávia Ferreira de Castro Paula*, José Aparecido Sorratini, Thays Pereira Silva \\ Triângulo University Center - Brazil, Federal University of Uberlândia - Brazil, Triângulo University Center - Brazil
}

Submitted 6 May 2013; received in revised form 30 Sep 2013; accepted 1 Nov 2013

\begin{abstract}
Resumo
O objetivo deste estudo é caracterizar o padrão de viagens geradas por quatro Instituições de Ensino Superior privadas, denominadas de IES-A, IES-B, IES-C e IES-D, na cidade de Uberlândia, MG, em função do tipo de usuário, turno de funcionamento e curso de graduação oferecido, além de identificar os principais modos de transporte motorizado e não motorizado. Após aplicação de um questionário à comunidade universitária foi possível caracterizar o padrão para as viagens atraídas e produzidas, identificando o período da viagem, o modo de transporte, o local de origem e destino das viagens, a localização física do local de origem e destino e, por fim, o tempo de viagem. Notou-se uma constância para o turno noturno do número de viagens atraídas ao longo da semana. Para os demais turnos verificou-se que a sexta-feira apresentou uma menor quantidade de viagens quando comparada com os demais dias da semana, tanto para o turno da manhã quanto para o da tarde. Este trabalho pode contribuir para a definição de modelos de geração de viagens para instituições privadas de ensino superior do Brasil, que têm características diferentes das instituições estrangeiras, principalmente dos EUA.
\end{abstract}

Palavras-Chave: polo gerador de viagem, instituição de ensino superior, caracterização do padrão de viagens.

\section{Abstract}

The objective of this study is to characterize the standard of the trips generated by four private universities, named as IES-A, IES-B, IES-C and IES-D, of the city of Uberlândia, MG, according to the type of user, time of operation and course offered, together with identifying the main transportation modes utilized by the users. After applying a survey to the university community it was possible to characterize the standard for the attracted and produced trips for the different transportation modes, to identify the time period of the trip, the transportation mode, the trips' origin and destination, the physical location of the trip' origin and destination and, finally, the trip time. It was observed constancy for the night-time shift of the number of trips attracted throughout the week. For the other shifts it was verified that the Friday presented a lesser amount of trips when compared with the other week days for both, the morning and the afternoon shifts. This work can contribute for the definition of trip generation models for private universities of Brazil, which have different characteristics when compared with foreign institutions, mainly of the USA.

Key words: trip generator, universities, trip standard.

*Email: anaffc@yahoo.com.br.

\section{Recommended Citation}

Paula, A. F. F. C., Sorratini, J. A. and Silva, T. P. (2014) Padrão de viagens geradas por instituições de ensino superior privadas da cidade de Uberlândia. Journal of Transport Literature, vol. 8, n. 3, pp. 107-138.

- JTL/RELIT is a fully electronic, peer-reviewed, open access, international journal focused on emerging transport markets and published by BPTS - Brazilian Transport Planning Society. Website www.transport-literature.org. ISSN 2238-1031. 


\section{Introdução}

Nos últimos anos tem crescido significativamente o número de novas Instituições de Ensino Superior, tanto no Brasil quanto no exterior. Os números coletados pelo Censo da Educação Superior, realizado pelo Instituto Nacional de Estudos e Pesquisas Educacionais Anísio Teixeira (INEP, 2009), existiam, em 2002 no Brasil, 1.637 Instituições de Ensino Superior (IES), das quais $88 \%$ eram privadas. Em 2008, esse número passou para 2.252, das quais $90 \%$ das IES eram privadas. Apesar disso, o número de pesquisas que têm como objetivo avaliar a interferência das viagens geradas pelo empreendimento instituição de ensino no trânsito em geral ainda é pequeno.

As instituições de ensino superior (IES), consideradas importantes Polos Geradores de Viagens (PGV), promovem um elevado número de viagens, oriundas do deslocamento realizado por alunos, professores e funcionários, por diferentes modos de transporte (motorizado e não motorizado). Segundo Souza (2007), nas instituições privadas a maioria das viagens é realizada por automóvel, o que causa impactos significativos no trânsito nas suas imediações. Tais impactos são acentuados pelo fato dos horários de início e término das aulas, em geral, coincidirem com os períodos de pico do tráfego.

Segundo Portugal e Goldner (2003), Polos Geradores de Viagens (PGV) são locais ou instalações de distintas naturezas que desenvolvem atividades de porte e escala capazes de produzir um contingente significativo de viagens.

Os PGV contribuem de forma significativa para o desenvolvimento das cidades. Nesse sentido, a localização de um PGV pode interferir no padrão de viagens produzidas, em indicadores socioeconômicos e demográficos e na conformação geográfica de uma região, bem como no seu nível de acessibilidade, que, de acordo com Andrade (2005), são os fatores consideráveis para o sucesso de um empreendimento. Segundo Rosa (2003), os polos geradores de viagem podem ser organizados segundo sua localização, como aqueles situados em centros urbanos e aqueles em áreas não urbanas ou periféricas. Nesse sentido, torna-se importante o estudo da localização de um PGV para que se facilitem as movimentações, tanto de pessoas quanto de carga, dentro das cidades (Portugal e Goldner, 2003). 
Segundo Nunes (2005), o planejamento e controle na implantação dos polos geradores de viagens tornam-se importante como forma de minimizar ou eliminar os impactos indesejáveis que possam ter sobre o transporte e o trânsito da sua área de influência, que são causas importantes das más condições de circulação nas cidades brasileiras. Portugal e Goldner (2003) enfatizam que é essencial no estudo de impactos de PGV, o conhecimento de critérios, de teorias de localização, de procedimentos e de taxas e modelos de geração de viagens.

Jacques et al. (2010) afirmam que os empreendimentos classificados como polos geradores de viagens, embora de diferentes naturezas, têm em comum o potencial de atrair e produzir um número de viagens que impactam os sistemas viários e de transportes da região onde se localizam. Dependendo das condições desses sistemas e do número de viagens geradas, a implantação dos mesmos pode trazer consequências bastante negativas para a qualidade de vida da população. Desse modo, é de suma importância que esses impactos mencionados anteriormente e a classificação dos empreendimentos considerados polos geradores de viagens seja considerada, visto que o tipo e o porte do empreendimento estão relacionados diretamente ao padrão e geração de viagens.

A geração de viagens é uma das etapas mais importantes do estudo de um PGV, pois, além de servir como instrumento para a análise da viabilidade de implantação do empreendimento, possibilita a identificação das viagens que realmente causarão mudanças na circulação das vias de acesso do mesmo (Portugal e Goldner, 2003). Os autores ainda complementam que, a partir da identificação do número de viagens geradas e da definição do dia e hora de projeto, é que se elaboram as demais etapas no estudo de impactos dos PGV.

Existem vários fatores que influenciam na geração de viagens de acordo com Ary (2002), sendo estes relativos às características do próprio empreendimento, como também da região onde ele está implantado. Dentre eles destacam-se o porte e atratividade do empreendimento, a tipologia das lojas instaladas, a localização, as condições de acessibilidade, as características socioeconômicas da região, o uso do solo no entorno e a existência de empreendimentos concorrentes.

Souza (2007) define padrão de viagens como um conjunto de viagens realizadas por motivos distintos, por diferentes modos, dentro de um período fixo de tempo, sendo que o modo como essas viagens são realizadas é influenciado por variáveis relacionadas ao PGV e ao usuário. 
Assim, para cada tipo de empreendimento, deve-se fazer um estudo específico, pois de acordo com a atividade desenvolvida, cada PGV possui um padrão de viagens específico.

De acordo com o ITE (2001), as viagens podem ser classificadas em diferentes categorias de acordo com o tipo do PGV. Tal classificação tem como objetivo determinar as taxas e modelos de geração de viagens que serão utilizadas nos estudos de planejamento do sistema viário. A identificação das viagens que realmente são geradas pela implantação de empreendimentos considerados como PGV é importante na etapa de geração de viagens e, principalmente, na etapa de alocação do tráfego.

Existem poucos estudos voltados para a caracterização do padrão de viagens de instituições de ensino superior (IES) foram realizados recentemente no Brasil. Dentre eles, destaca-se o de Souza (2007), que obervou em Brasília-DF, que os alunos das instituições de ensino superior avaliadas se deslocam até a mesma predominantemente por automóvel particular. Verificou também, que os discentes residem nas regiões mais próximas da IES. Segundo a autora, essa situação se justifica pelo fato da maioria das instituições avaliadas serem de pequeno porte, onde a atratividade do empreendimento não é acentuada.

Nesse sentido, busca-se com este trabalho caracterizar o padrão de viagens de quatro Instituições de Ensino Superior privadas, na cidade de Uberlândia, em função do tipo de usuário, turno de funcionamento e curso de graduação oferecido e identificar os principais modos de transporte, destinadas a subsidiar o planejamento urbano e de transporte nas proximidades das IES possam trazer melhorias significativas para as condições de mobilidade urbana, que incorporem, assim, princípios da sustentabilidade.

\section{Obtenção e Tratamento dos Dados}

A metodologia adotada neste trabalho deu-se a partir da obtenção e tratamento dos dados necessários para a caracterização dos padrões de viagens dos usuários das IES, com ênfase nas publicações de Souza (2007), Bertazzo (2008) e ITE (2001). Este trabalho está dividido em quatro etapas.

A primeira etapa da pesquisa consistiu em selecionar as instituições pesquisadas e definir o tamanho da amostra e o instrumento de coleta de dados. Neste trabalho foram avaliadas as 4 (quatro) instituições de ensino superior com maior número de alunos matriculados, dentre as 
10 existentes na cidade de Uberlândia e cadastradas no Ministério da Educação - MEC (MEC, 2012). Todas as quatro são instituições privadas com campus único.

A coleta de dados foi realizada por meio da aplicação de um questionário (Apêndice 1) os alunos das IES. Os dados relacionados às questões administrativas da IES, como o número e nome dos cursos de graduação presenciais, número de alunos ingressantes por ano, foram obtidos nos sites oficiais das instituições, bem como em MEC (2012). Após isso, tendo-se o tamanho da população (N) de cada IES, juntamente com a Equação 1, proposta por Barbetta (2004), é possível calcular o tamanho aproximado da população amostral de cada instituição. Essa metodologia foi adotada por Souza (2007) e Bertazzo (2008).

$$
n_{0}=\left(\frac{\frac{Z_{2}}{2}}{E_{0}}\right)^{2} \cdot p(1-p)
$$

A parte determinística $\mathrm{n}_{0}$, é uma primeira aproximação para o tamanho da amostra, $\mathrm{Z}_{\alpha / 2}$ consiste no valor crítico que corresponde ao grau de confiança desejado. Neste caso, considerar-se-á um $\alpha=5 \%$ e, consequentemente, $\mathrm{Z}_{\alpha / 2}=1,96, \mathrm{E}_{0}$ é o erro amostral tolerável (no estudo será igual a 5\%), e por fim, p consiste na proporção da variável de interesse na população (para uma estimativa conservadora de $\mathrm{n}_{0}$, adotar-se-á $\mathrm{p}=0,5$ ).

Ao se conhecer o tamanho da população $(\mathrm{N})$ é possível corrigir o valor anterior $\mathrm{n}_{0}$ usando a Equação 2 (Barbetta, 2004).

$$
n_{t}=\frac{N \cdot n_{0}}{N+n_{0}}
$$

Onde $\mathrm{n}_{\mathrm{t}}$ consiste no tamanho da amostra necessária para cada IES por turno.

Com o objetivo de abranger o maior número amostral possível, neste trabalho foram avaliados, caso existam, os três turnos de funcionamento das IES (manhã, tarde e noite). Para cada turno foram obtidos o nome dos cursos, o número de alunos para se determinar o tamanho da amostra (n) e aplicação dos questionários em cada turno. Uma IES privada pode apresentar uma heterogeneidade socioeconômica no seu corpo discente, ou seja, os alunos do turno da manhã podem ter um nível socioeconômico mais elevado do que os alunos do turno noturno. Como essa heterogeneidade pode influenciar diretamente no modo de transportes utilizado optou-se por aplicar o questionário a todos os cursos em todos os turnos. Como os 
cursos possuem, normalmente, número de alunos diferentes, o número de questionários aplicados, em cada curso, foi ponderado em função dessa condição (Equação 3).

$$
n_{c}=\frac{n_{t}}{N_{t}} \cdot N_{c}
$$

Em que $\mathrm{n}_{\mathrm{c}}$ consiste no número de questionários a serem aplicados em cada curso, $\mathrm{n}_{\mathrm{t}}$ é o tamanho da amostra necessária em cada turno, $\mathrm{N}_{\mathrm{t}}$, o tamanho da população em cada turno e $\mathrm{N}_{\mathrm{c}}$, o número de alunos matriculados ou professores ou funcionários de cada curso.

$\mathrm{Na}$ segunda etapa foi realizada a aplicação do questionário. Foram realizadas visitas às 04 (quatro) instituições para apresentar a pesquisa e solicitar a colaboração das mesmas na obtenção dos dados e aplicação dos questionários junto aos alunos. A aplicação do questionário nas IES foi realizada no período de março a junho de 2012. Nesta etapa contouse com a colaboração de quatro estagiárias, as quais ficaram responsáveis pela aplicação dos questionários nas instituições.

O questionário destinado aos alunos foi aplicado em sala de aula pelas estagiárias com a permissão do professor responsável. Para os cursos em regime integral, cuja predominância das aulas é pela manhã e à tarde, foram escolhidos por sorteio dois períodos com predominância das aulas na parte da manhã e dois na parte da tarde. Para os cursos com predominância das aulas em um único turno, também foram escolhidas por sorteio dois períodos, nos quais o questionário foi aplicado. Os períodos sorteados para aplicação do questionário foram o $1^{\underline{o}}$ e o $4^{\underline{0}}$.

Já na terceira etapa, para organizar os dados encontrados nos questionários preenchidos pelos usuários de cada instituição e, posteriormente, extrair informações por meio de gráficos e planilhas que auxiliaram na caracterização das viagens dos usuários, fez-se necessário a utilização da planilha eletrônica Excel. Para tanto, foi criado um formulário, onde os dados dos questionários foram digitados. Como a atividade é repetitiva, devido ao grande número de informações, foi editada uma "macro" para controlar a gravação dos dados em uma planilha ou, neste caso, o banco de dados.

Após a obtenção e compilação dos dados, foi possível, através da quarta etapa, a caracterização dos padrões de viagens dos alunos das IES, para as viagens atraídas e produzidas, para os diferentes modos de transporte. A caracterização do padrão de viagens 
dos usuários requer a identificação de cinco fatores importantes: período da viagem; modo de transporte; local de origem e destino das viagens; localização física do local de origem e destino; e tempo de viagem.

\section{Resultados e Discussões}

Neste trabalho foram avaliadas quatro instituições de ensino superior localizadas na cidade de Uberlândia, MG, denominadas de IES-A, IES-B, IES-C e IES-D. No que diz respeito ao zoneamento verifica-se, por meio da Tabela 1, que as IES-A, B e C estão localizadas na Zona Sul da cidade, a qual se caracteriza como de uso residencial (Uberlândia, 2012). A IES-A está situada em uma via de trânsito rápido $(70 \mathrm{~km} / \mathrm{h})$, o que favorece uma maior fluidez das viagens geradas e atraídas por ela. As IES-B e C estão localizadas em vias arteriais, que, normalmente, têm menor capacidade de tráfego que a via de trânsito rápido e, portanto, em uma situação de tráfego mais intenso poderia haver transtornos no seu trânsito do entorno. Verificou-se que todas as três IES possuem capacidade para absorver sua demanda interna por estacionamento.

Tabela 1 - Características de zoneamento e uso e ocupação do solo das IES

\begin{tabular}{|c|c|c|}
\hline Instituição & Zoneamento (zona) & Uso do Solo \\
\hline IES-A & Sul & Zona Residencial 3-ZR3 \\
\hline IES-B & Sul & Zona Residencial 3 - ZR3 \\
\hline IES-C & Sul & Zona Residencial 1 - ZR1 \\
\hline IES-D & Central & Zona Central $2-\mathrm{ZC} 2$ \\
\hline
\end{tabular}

Por outro lado, a IES-D se diferencia das demais por localizar-se na Zona Central da cidade, onde a ocupação do solo é mista (Uberlândia, 2012), ou seja, há residências, comércio e serviços na região. Ela está situada em uma via de mão única de tráfego, com apenas uma entrada e sem estacionamento interno, o que favorece a ocorrência de pontos de retenção do trânsito de veículos devido às manobras de estacionamento.

As instituições analisadas neste trabalho concentram suas atividades no ensino de graduação presencial, onde a maioria dos alunos frequentam as aulas no período noturno. Verificou-se que a IES-A possuía na época da pesquisa, em 2012, 6.682 mil alunos matriculados, e oferecia 20 cursos de graduação, nos três turnos - manhã (M), tarde (T) e noite (N). A IES-B possuía 2.083 alunos matriculados, e oferecia 11 cursos de graduação, todos no período 
noturno. A IES-C possuía 1.729 alunos matriculados, e oferecia 15 cursos, nos períodos matutino e noturno. A IES-D possuía 1.198 alunos matriculados, e oferecia 9 cursos, nos três turnos. Na Tabela 2 são apresentados o número total de alunos e a amostra necessária de questionários aplicados nas IES-A, B, C e D. A amostra necessária de alunos foi calculada por meio da Equação 2.

Tabela 2 - Dados do número total de alunos, e a amostra necessária de questionários aplicados nas IES-A, B, C e D

\begin{tabular}{cccc}
\hline IES & Turno & Total & Amostra necessária \\
\hline \multirow{2}{*}{ IES-A } & Manhã & 2.018 & 323 \\
& Tarde & 137 & 101 \\
\multirow{2}{*}{ IES-B } & Noite & 4.527 & 355 \\
& Noite & 2.083 & 325 \\
\multirow{2}{*}{ IES-C } & Manhã & 330 & 178 \\
& Noite & 1399 & 302 \\
& Manhã & 184 & 124 \\
IES-D & Tarde & 118 & 90 \\
& Noite & 896 & 269 \\
\hline
\end{tabular}

Nas Tabelas 3 a 6 são mostrados os dados referentes a alunos, coletados por curso e por turno, nas IES-A, B, C e D, respectivamente.

Tabela 3 - Amostra de alunos necessários e coletados por curso na IES-A

\begin{tabular}{|c|c|c|c|c|c|c|c|c|c|}
\hline \multirow[t]{2}{*}{ Curso } & \multicolumn{3}{|c|}{$\begin{array}{c}\text { Total de alunos por } \\
\text { turno }\end{array}$} & \multicolumn{3}{|c|}{$\begin{array}{l}\text { Amostra de alunos } \\
\text { necessária por turno }\end{array}$} & \multicolumn{3}{|c|}{$\begin{array}{l}\text { Amostra de alunos } \\
\text { coletada por turno }\end{array}$} \\
\hline & $\mathbf{M}^{1}$ & $\mathbf{T}^{2}$ & $\mathbf{N}^{3}$ & M & $\mathbf{T}$ & $\mathbf{N}$ & $\mathbf{M}$ & $\mathbf{T}$ & $\mathbf{N}$ \\
\hline Administração & $\ldots$ & $\ldots$ & 324 & $\ldots$ & $\ldots$ & 25 & $\ldots$ & $\ldots$ & 23 \\
\hline Agronomia & $\ldots$ & $\ldots$ & 110 & $\ldots$ & $\ldots$ & 9 & $\ldots$ & $\ldots$ & 8 \\
\hline Arquitetura e Urbanismo & 430 & $\ldots$ & $\ldots$ & 69 & $\ldots$ & $\ldots$ & 67 & $\ldots$ & $\ldots$ \\
\hline Biologia (licenciatura) & $\ldots$ & $\ldots$ & 103 & $\ldots$ & $\ldots$ & 8 & $\ldots$ & $\ldots$ & 8 \\
\hline Ciências Contábeis & $\ldots$ & $\ldots$ & 196 & $\ldots$ & $\ldots$ & 15 & $\ldots$ & $\ldots$ & 13 \\
\hline Ciência da Computação & $\ldots$ & $\ldots$ & 177 & $\ldots$ & $\ldots$ & 14 & $\ldots$ & $\ldots$ & 14 \\
\hline Design de Moda & $\ldots$ & $\ldots$ & 79 & $\ldots$ & $\ldots$ & 6 & $\ldots$ & $\ldots$ & 6 \\
\hline Direito & 358 & $\ldots$ & 836 & 57 & $\ldots$ & 66 & $\ldots$ & $\ldots$ & 61 \\
\hline Educação Física & $\ldots$ & $\ldots$ & 323 & $\ldots$ & $\ldots$ & 25 & $\ldots$ & $\ldots$ & 24 \\
\hline Enfermagem & 69 & $\ldots$ & 187 & 11 & $\ldots$ & 15 & $\ldots$ & $\ldots$ & 14 \\
\hline Engenharia Civil & $\ldots$ & $\ldots$ & 525 & $\ldots$ & $\ldots$ & 41 & $\ldots$ & $\ldots$ & 39 \\
\hline Engenharia de Produção & $\ldots$ & $\ldots$ & 307 & $\ldots$ & $\ldots$ & 24 & $\ldots$ & $\ldots$ & 23 \\
\hline Farmácia & 114 & $\ldots$ & 159 & 18 & $\ldots$ & 12 & $\ldots$ & $\ldots$ & 12 \\
\hline Fisioterapia & 308 & $\ldots$ & 25 & 49 & $\ldots$ & 2 & 51 & $\ldots$ & $\ldots$ \\
\hline Medicina Veterinária & 23 & $\ldots$ & 42 & 4 & $\ldots$ & 3 & $\ldots$ & $\ldots$ & 7 \\
\hline Nutrição & 80 & $\ldots$ & 221 & 13 & $\ldots$ & 17 & $\ldots$ & $\ldots$ & $\ldots$ \\
\hline Odontologia & 200 & 137 & $\ldots$ & 32 & 101 & $\ldots$ & $\ldots$ & $\ldots$ & $\ldots$ \\
\hline Psicologia & 233 & $\ldots$ & 287 & 37 & $\ldots$ & 22 & $\ldots$ & $\ldots$ & $\ldots$ \\
\hline Sistemas de Informação & $\ldots$ & $\ldots$ & 360 & $\ldots$ & $\ldots$ & 28 & $\ldots$ & $\ldots$ & 27 \\
\hline Tecnólogo em Estética & 203 & $\ldots$ & 266 & 33 & $\ldots$ & 21 & $\ldots$ & $\ldots$ & 20 \\
\hline
\end{tabular}

${ }^{1} \mathrm{M}=$ manhã $;{ }^{2} \mathrm{~T}=$ tarde $;{ }^{3} \mathrm{~N}=$ noite $;. . .=$ dado numérico inexistente 
Tabela 4 - Dados necessários e coletados por curso na IES-B

\begin{tabular}{|c|c|c|c|c|c|c|c|c|c|}
\hline \multirow[t]{2}{*}{ Curso } & \multicolumn{3}{|c|}{$\begin{array}{l}\text { Total de alunos } \\
\text { por turno }\end{array}$} & \multicolumn{3}{|c|}{$\begin{array}{l}\text { Amostra de alunos } \\
\text { necessária por turno }\end{array}$} & \multicolumn{3}{|c|}{$\begin{array}{l}\text { Amostra de alunos } \\
\text { coletada por turno }\end{array}$} \\
\hline & $\mathbf{M}^{1}$ & $\mathbf{T}^{2}$ & $\mathbf{N}^{3}$ & $\mathbf{M}$ & $\mathbf{T}$ & $\mathbf{N}$ & $\mathbf{M}$ & $\mathbf{T}$ & $\mathbf{N}$ \\
\hline Administração & $\ldots$ & $\ldots$ & 197 & $\ldots$ & $\ldots$ & 31 & $\ldots$ & $\ldots$ & 32 \\
\hline Ciências Contábeis & $\ldots$ & $\ldots$ & 272 & $\ldots$ & $\ldots$ & 42 & $\ldots$ & $\ldots$ & 42 \\
\hline Direito & $\ldots$ & $\ldots$ & 312 & $\ldots$ & $\ldots$ & 49 & $\ldots$ & $\ldots$ & 49 \\
\hline $\begin{array}{l}\text { Engenharia de Controle e } \\
\text { Automação }\end{array}$ & ... & $\ldots$ & 137 & $\cdots$ & $\ldots$ & 21 & $\ldots$ & $\ldots$ & 22 \\
\hline Engenharia de Produção & $\ldots$ & $\ldots$ & 105 & $\ldots$ & $\ldots$ & 16 & $\ldots$ & $\ldots$ & 17 \\
\hline Engenharia Elétrica & $\ldots$ & $\ldots$ & 234 & $\ldots$ & $\ldots$ & 36 & $\ldots$ & $\ldots$ & 29 \\
\hline Engenharia Mecânica & $\ldots$ & $\ldots$ & 230 & $\ldots$ & $\ldots$ & 36 & $\ldots$ & $\ldots$ & 37 \\
\hline Gestão de Marketing & $\ldots$ & $\ldots$ & 83 & $\ldots$ & $\ldots$ & 13 & $\ldots$ & $\ldots$ & 16 \\
\hline $\begin{array}{l}\text { Gestão de Recursos } \\
\text { Humanos }\end{array}$ & $\cdots$ & $\cdots$ & 193 & $\cdots$ & $\cdots$ & 30 & $\cdots$ & $\ldots$ & 31 \\
\hline Gestão Financeira & $\ldots$ & $\ldots$ & 97 & $\ldots$ & $\ldots$ & 15 & $\ldots$ & $\ldots$ & 16 \\
\hline Sistema da Informação & $\ldots$ & $\ldots$ & 223 & $\ldots$ & $\ldots$ & 35 & $\ldots$ & $\ldots$ & 36 \\
\hline
\end{tabular}

${ }^{\mathrm{T}} \mathrm{M}=$ manhã $;{ }^{2} \mathrm{~T}=\operatorname{tarde} ;{ }^{3} \mathrm{~N}=$ noite $; \ldots=$ dado numérico inexistente

Tabela 5 - Dados necessários e coletados por curso na IES-C

\begin{tabular}{l|c|c|c|c|c|c|c|c|c}
\hline \multirow{2}{*}{ Curso } & \multicolumn{3}{|c|}{$\begin{array}{c}\text { Total de alunos por } \\
\text { turno }\end{array}$} & \multicolumn{3}{c}{$\begin{array}{c}\text { Amostra de alunos } \\
\text { necessária por turno }\end{array}$} & \multicolumn{3}{c}{$\begin{array}{c}\text { Amostra de alunos } \\
\text { coletada por turno }\end{array}$} \\
\cline { 2 - 9 } & $\mathbf{M}^{1}$ & $\mathbf{T}^{2}$ & $\mathbf{N}^{3}$ & $\mathbf{M}$ & $\mathbf{T}$ & $\mathbf{N}$ & $\mathbf{M}$ & $\mathbf{T}$ & $\mathbf{N}$ \\
\hline Administração & $\ldots$ & $\ldots$ & 211 & $\ldots$ & $\ldots$ & 46 & $\ldots$ & $\ldots$ & 48 \\
Ciências Contábeis & $\ldots$ & $\ldots$ & 53 & $\ldots$ & $\ldots$ & 11 & $\ldots$ & $\ldots$ & 14 \\
Direito - Matutino & 66 & $\ldots$ & $\ldots$ & 36 & $\ldots$ & & 18 & $\ldots$ & $\ldots$ \\
Direito - Noturno & $\ldots$ & $\ldots$ & 132 & $\ldots$ & $\ldots$ & 28 & $\ldots$ & $\ldots$ & 31 \\
Engenharia Ambiental & $\ldots$ & $\ldots$ & 132 & $\ldots$ & $\ldots$ & 28 & $\ldots$ & $\ldots$ & 31 \\
Engenharia Civil - Matutino & 132 & $\ldots$ & $\ldots$ & 71 & $\ldots$ & & 4 & $\ldots$ & $\ldots$ \\
Engenharia Civil - Noturno & $\ldots$ & $\ldots$ & 132 & $\ldots$ & $\ldots$ & 28 & $\ldots$ & $\ldots$ & 31 \\
Engenharia Elétrica & $\ldots$ & $\ldots$ & 132 & $\ldots$ & $\ldots$ & 28 & $\ldots$ & $\ldots$ & 31 \\
Engenharia Mecânica & $\ldots$ & $\ldots$ & 132 & $\ldots$ & $\ldots$ & 28 & $\ldots$ & $\ldots$ & 31 \\
Logística & $\ldots$ & $\ldots$ & 53 & $\ldots$ & $\ldots$ & 11 & $\ldots$ & $\ldots$ & 12 \\
Pedagogia & $\ldots$ & $\ldots$ & 92 & $\ldots$ & $\ldots$ & 20 & $\ldots$ & $\ldots$ & 22 \\
Psicologia & 132 & $\ldots$ & $\ldots$ & 71 & $\ldots$ & & 40 & $\ldots$ & $\ldots$ \\
Recursos Humanos & $\ldots$ & $\ldots$ & 53 & $\ldots$ & $\ldots$ & 11 & $\ldots$ & $\ldots$ & 11 \\
Redes de Computadores & $\ldots$ & $\ldots$ & 66 & $\ldots$ & $\ldots$ & 14 & $\ldots$ & $\ldots$ & 15 \\
Sistema da Informação & $\ldots$ & $\ldots$ & 211 & $\ldots$ & $\ldots$ & 46 & $\ldots$ & $\ldots$ & 50 \\
\hline
\end{tabular}

${ }^{\mathrm{T}} \mathrm{M}=$ manhã; ${ }^{2} \mathrm{~T}=\operatorname{tarde} ;{ }^{3} \mathrm{~N}=$ noite $; \ldots=$ dado numérico inexistente

Tabela 6 - Dados necessários e coletados por curso na IES-D

\begin{tabular}{l|c|c|c|c|c|c|c|c|c}
\hline \multirow{2}{*}{ Curso } & \multicolumn{3}{|c|}{$\begin{array}{c}\text { Total de alunos por } \\
\text { turno }\end{array}$} & \multicolumn{2}{c|}{$\begin{array}{c}\text { Amostra de alunos } \\
\text { necessária por turno }\end{array}$} & \multicolumn{2}{c}{$\begin{array}{c}\text { Amostra de alunos } \\
\text { coletada por turno }\end{array}$} \\
\cline { 2 - 9 } & $\mathbf{M}^{\mathbf{1}}$ & $\mathbf{T}^{\mathbf{2}}$ & $\mathbf{N}^{\mathbf{3}}$ & $\mathbf{M}$ & $\mathbf{T}$ & $\mathbf{N}$ & $\mathbf{M}$ & $\mathbf{T}$ & $\mathbf{N}$ \\
\hline Administração & $\ldots$ & $\ldots$ & 37 & $\ldots$ & $\ldots$ & 11 & $\ldots$ & $\ldots$ & 14 \\
Direito & $\ldots$ & $\ldots$ & 256 & $\ldots$ & $\ldots$ & 77 & $\ldots$ & $\ldots$ & 46 \\
Filosofia & 34 & $\ldots$ & $\ldots$ & 23 & $\ldots$ & $\ldots$ & 0 & $\ldots$ & $\ldots$ \\
Geografia (licenciatura) & $\ldots$ & $\ldots$ & 14 & $\ldots$ & $\ldots$ & 4 & $\ldots$ & $\ldots$ & 4 \\
Gestão Ambiental (tecnólogo) & $\ldots$ & $\ldots$ & 35 & $\ldots$ & $\ldots$ & 11 & $\ldots$ & $\ldots$ & 11 \\
História & $\ldots$ & $\ldots$ & 17 & $\ldots$ & $\ldots$ & 5 & $\ldots$ & $\ldots$ & 0 \\
Logística (tecnólogo) & $\ldots$ & $\ldots$ & 32 & $\ldots$ & $\ldots$ & 10 & $\ldots$ & $\ldots$ & 19 \\
Pedagogia (bacharelado) & $\ldots$ & $\ldots$ & 254 & $\ldots$ & $\ldots$ & 76 & $\ldots$ & $\ldots$ & 43 \\
Pedagogia (licenciatura) & 150 & $\ldots$ & $\ldots$ & 101 & $\ldots$ & $\ldots$ & 48 & $\ldots$ & $\ldots$ \\
Serviço Social (bacharelado) & $\ldots$ & 118 & 223 & $\ldots$ & 90 & 67 & $\ldots$ & 0 & 67 \\
Teologia (bacharelado) & $\ldots$ & $\ldots$ & 28 & $\ldots$ & $\ldots$ & 8 & $\ldots$ & $\ldots$ & 8 \\
\hline
\end{tabular}

${ }^{\mathrm{T}} \mathrm{M}=$ manhã $;{ }^{2} \mathrm{~T}=$ tarde $;{ }^{3} \mathrm{~N}=$ noite; $\ldots=$ dado numérico inexistente 
Com base nas Tabelas 3 a 6 verifica-se que a atividade acadêmica nas instituições A, C e D se concentra no período noturno e na IES B é exclusivamente nesse período. Em todos os casos, a amostra necessária de alunos por turno foi calculada por meio da Equação 3, considerando um erro inicial de $5 \%$.

\subsection{Caracterização do padrão de viagens}

O primeiro item analisado foi o período das viagens. Para tanto, foi considerado o número de viagens atraídas e produzidas por dia e por turno para cada instituição estudada. Entretanto, para os itens modo de transporte utilizado, local de origem e destino das viagens, localização do local de origem e destino e tempo de viagem foram considerados a média do número de viagens atraídas e produzidas por semana e por turno. Sendo assim, as instituições passaram a ser analisadas por turno: IES-A manhã, IES-A tarde, IES-A noite, IES-B noite, IES-C manhã, IES-C noite, IES-D manhã, IES-D tarde e IES-D noite. É importante ressaltar que se optou por dividir as IES por turno (manhã, tarde e noite) para que não descaracterizasse os resultados encontrados em cada turno, visto que há uma significativa variação entre eles, principalmente no período da noite. Ressalta-se que os dados apresentados não foram expandidos.

As IES-B e IES-C não apresentam cursos no turno da tarde, conforme apresentado na Tabela 2, contudo, na compilação dos dados dos questionários verificou-se a presença de algumas viagens nesse turno. Essa situação se explica pelo fato de existirem alunos que frequentam a instituição neste período para a realização de pesquisas científicas, estágios, dentre outras atividades acadêmicas.

\subsubsection{Período das viagens}

O período das viagens atraídas e produzidas pelos alunos são apresentados para os dias da semana, de segunda-feira a sábado, e para os períodos, manhã, tarde e noite. A partir dessas informações foi possível identificar os períodos e os dias mais críticos de viagens de cada IES. Nas Figuras 1 a 3 são apresentados os totais de viagens atraídas para os usuários alunos, nos turnos manhã, tarde e noite, respectivamente, para cada IES pesquisada. 


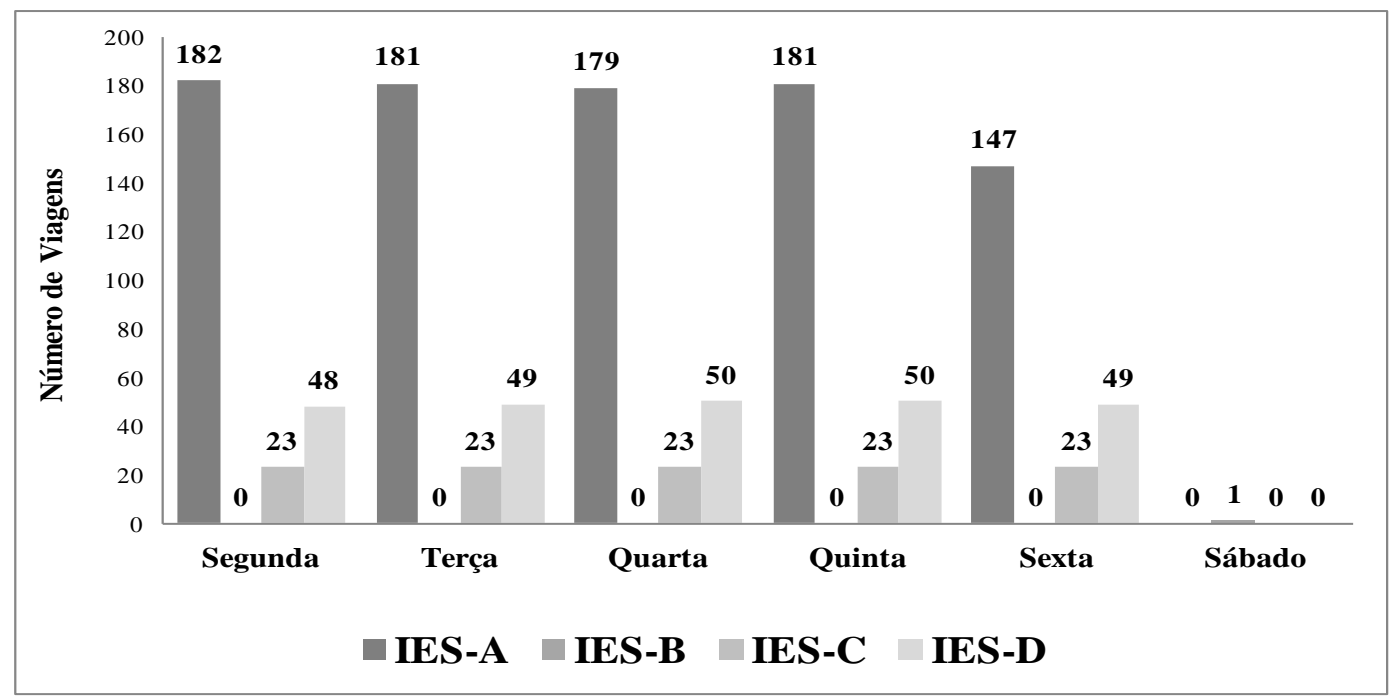

Figura 1 - Total de viagens atraídas no turno da manhã por aluno

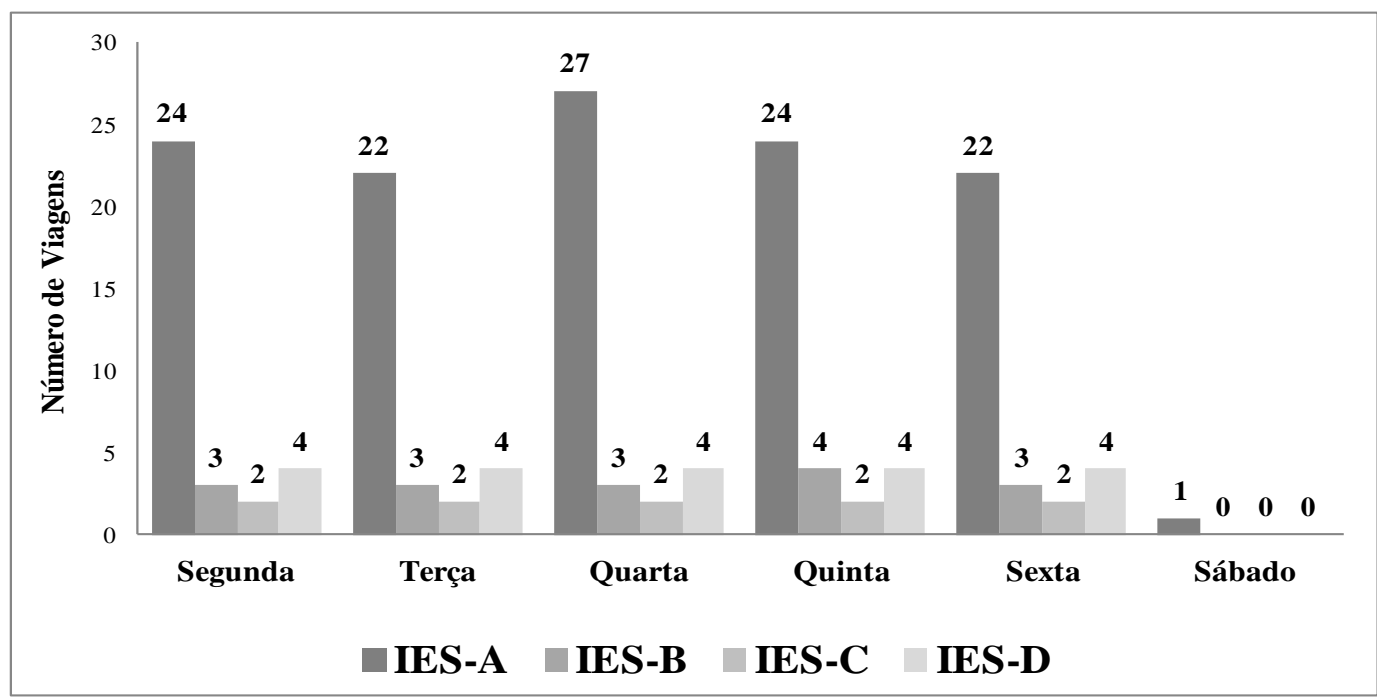

Figura 2 - Total de viagens atraídas no turno da tarde por aluno

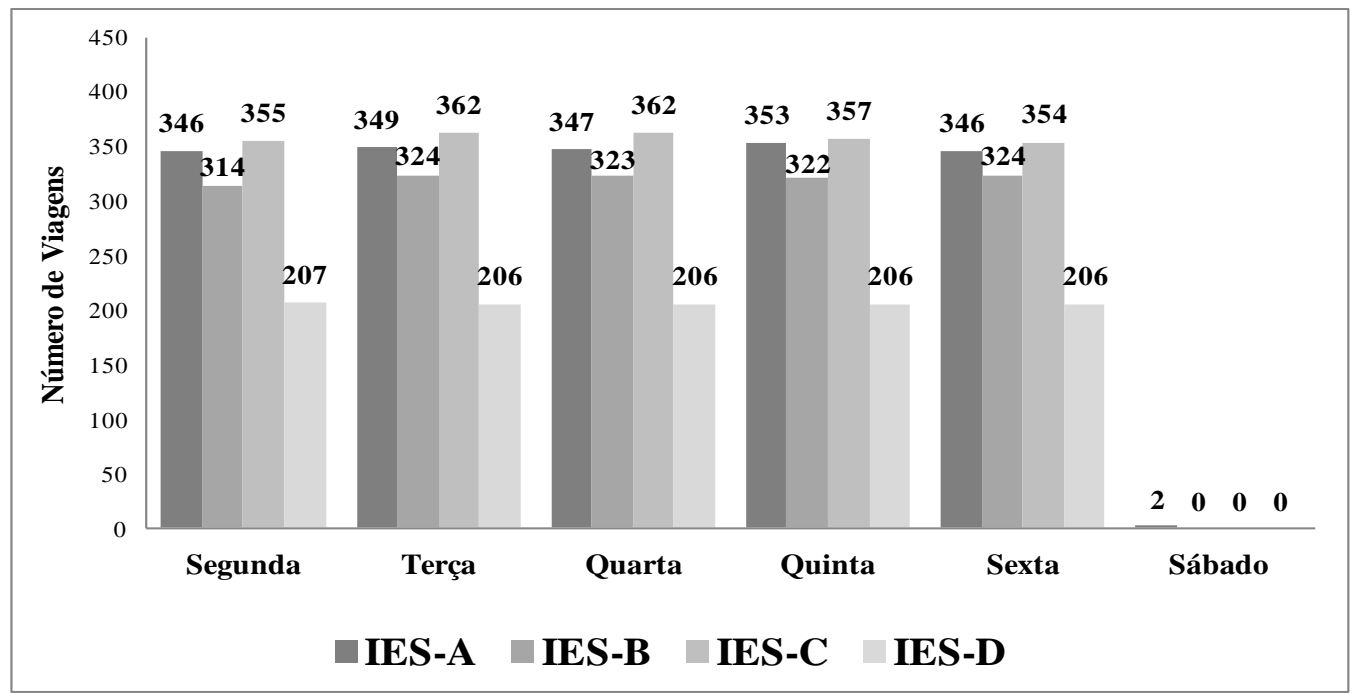

Figura 3 - Total de viagens atraídas no turno da noite por aluno 
De forma geral, existe uma constância do número de viagens atraídas ao longo da semana somente para o período noturno. Para os demais turnos notou-se que a sexta-feira, tanto para o período da manhã quanto para o período da tarde, apresenta uma menor quantidade de viagens quando comparada com os demais dias da semana. No sábado, o fluxo de viagens cai consideravelmente em todas as instituições, em virtude da baixa quantidade de aulas existentes nas IES.

Outro fator a ser considerado foi a grande quantidade de usuários no turno da noite para as quatro IES em estudo, visto que a maioria dos alunos que estudam nas instituições particulares opta pelo turno da noite por trabalharem durante o dia.

Conforme apresentado na Figura 2, existem algumas viagens atraídas no período da tarde, nas IES-B e IES-C. Essa situação se explica pelo fato de existirem alunos que frequentam a instituição neste período, para a realização de pesquisas científicas, estágios, dentre outras atividades acadêmicas.

Nas Figuras 4 a 6 são apresentados os totais de viagens produzidas para os usuários alunos, nos turnos manhã, tarde e noite, respectivamente, para cada IES pesquisada.

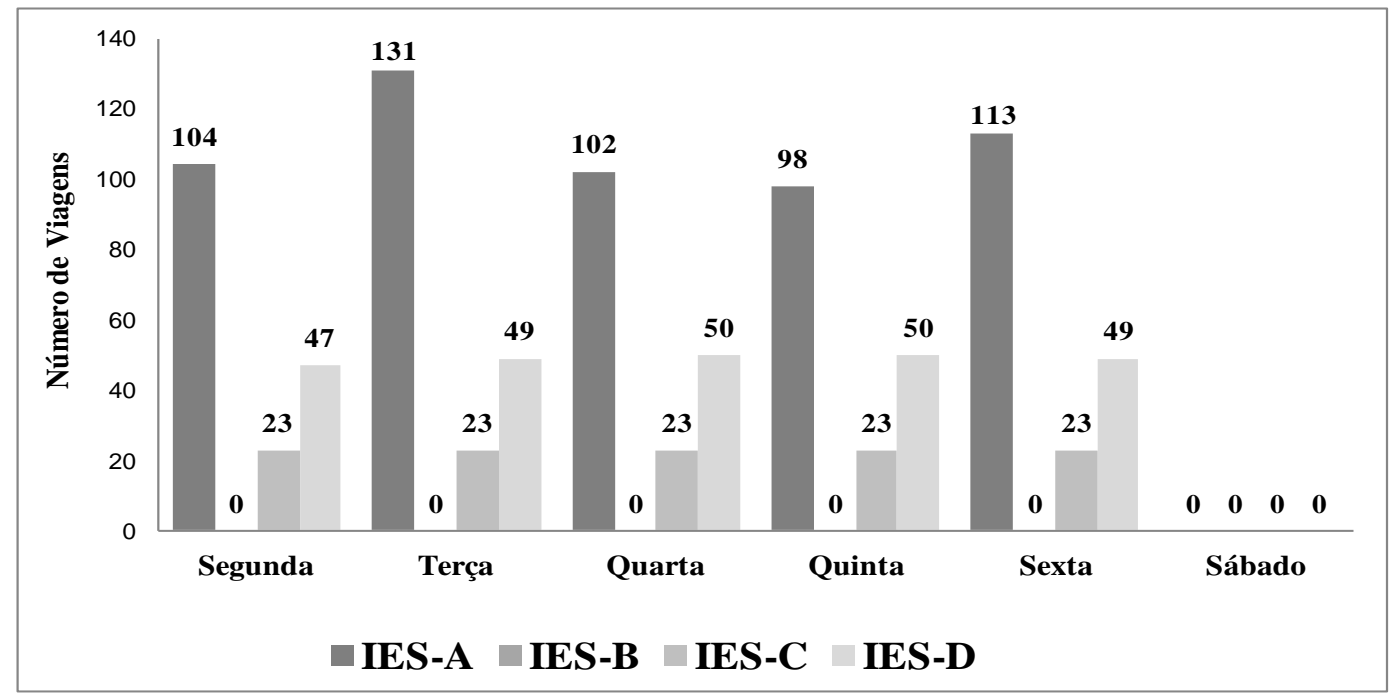

Figura 4 - Total de viagens produzidas no turno da manhã por aluno 


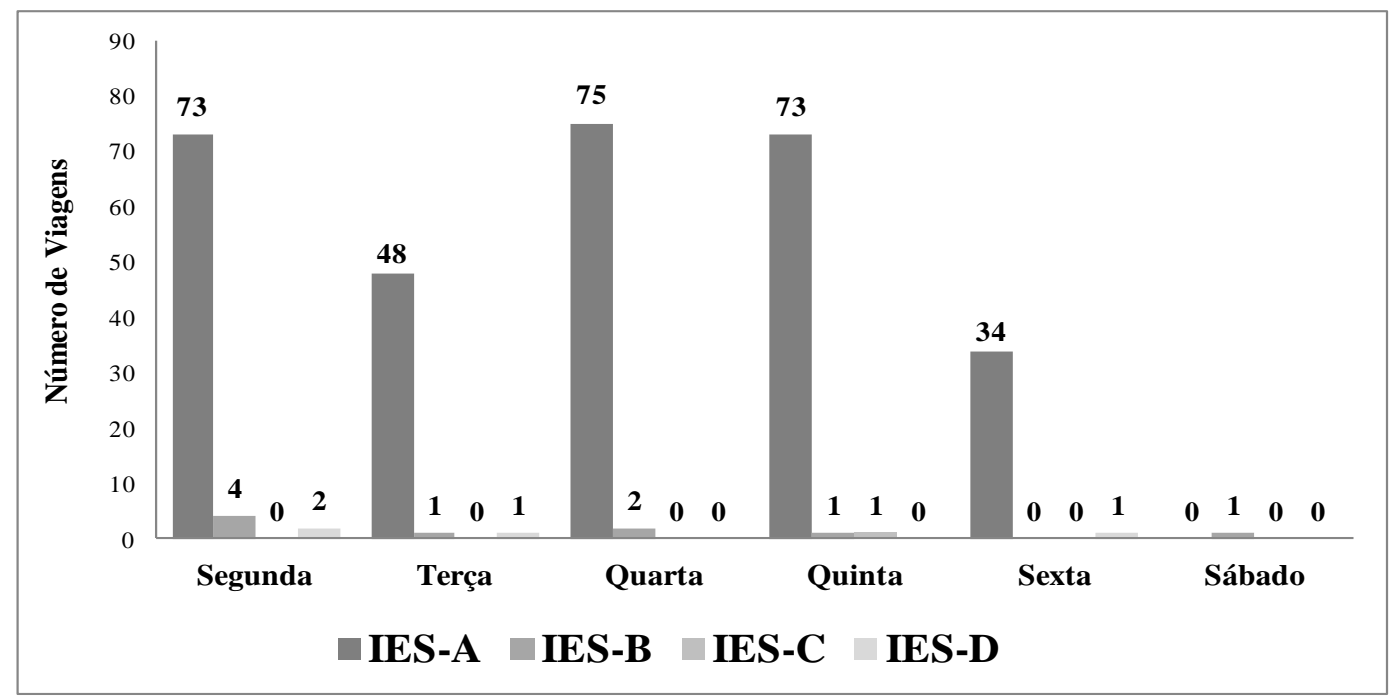

Figura 5 - Total de viagens produzidas no turno da tarde por aluno

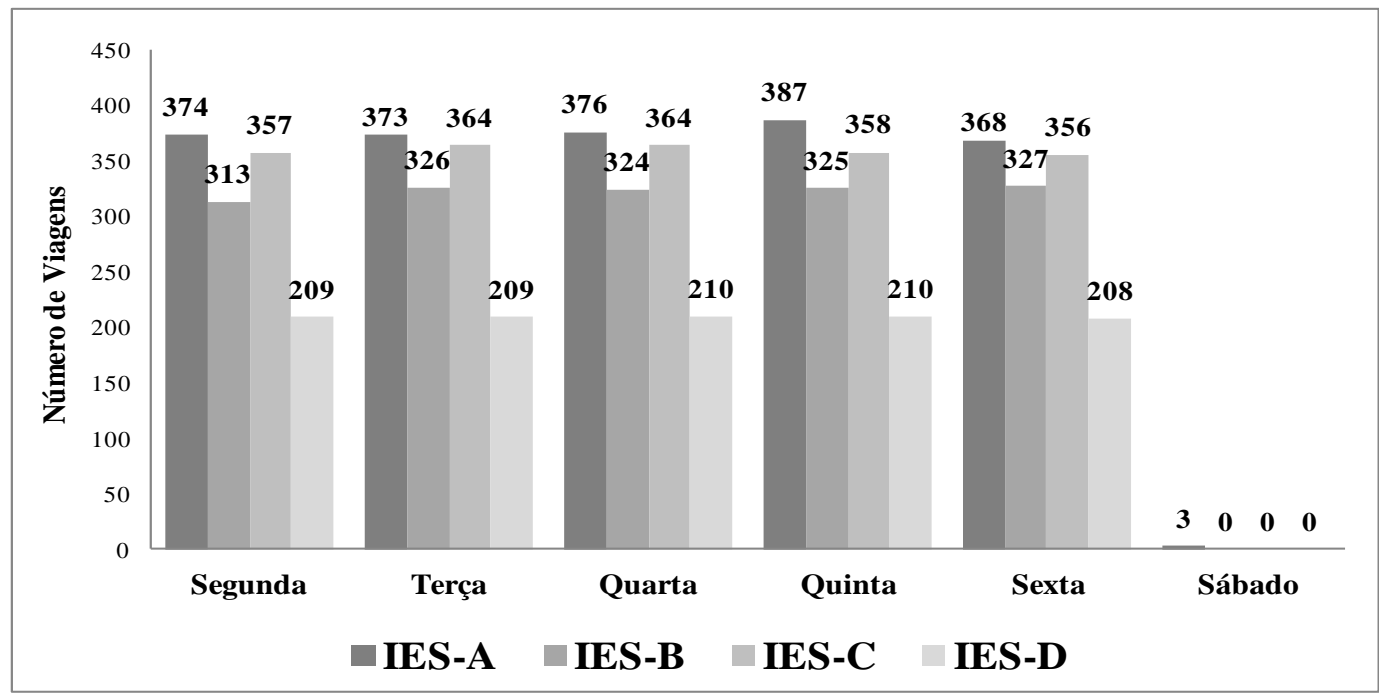

Figura 6 - Total de viagens produzidas no turno da noite por aluno

Conforme apresentado na Figura 5 o menor número de viagens produzidas no turno da tarde, para a IES-A, acontece nas terças e sextas-feiras. Nos demais dias há pouca variação, de 73 a 75 viagens. Para as demais instituições, IES-B, IES-C e IES-D, a quantidade de viagens produzidas é baixa comparado com a IES-A.

Além disso, observa-se na citada figura, que existem algumas viagens produzidas no período da tarde, nas IES-B e IES-C, apesar das mesmas não oferecerem cursos nesse turno. Essa situação se explica pelo fato de existirem alunos que frequentam a instituição neste período, para a realização de pesquisas científicas, estágios, dentre outras atividades acadêmicas. Observa-se também, que o número de viagens atraídas no turno da tarde (Figura 2), é maior 
do que as produzidas (Figura 5). Isso se justifica pelo fato de alguns alunos entrarem na instituição no turno da tarde e saírem no turno da noite, após a aula.

Observa-se que o turno da noite é o que apresenta o maior número de viagens atraídas e produzidas, conforme mostram as Figuras 3 e 6. Com relação à IES-A, os dias que possuem maior e menor número de viagens produzidas no turno da noite são, quinta e sexta-feira, respectivamente. Para a IES-B, a segunda-feira é o dia com menor número de viagens produzidas, sendo que no restante da semana não há uma variação significativa. As IES-C e IES-D possuem uma baixa variação no total de viagens produzidas ao longo dos dias da semana no turno da noite.

Quanto ao dia crítico para as viagens produzidas no turno da manhã observou-se que não houve variação significativa, com exceção do sábado, que apresentou valores baixos para todas as instituições. Contudo, é possível afirmar que a terça-feira é considerada o dia de maior movimento de viagens produzidas para a IES-A no turno da manhã, e a quinta-feira, o dia de menor número de viagens produzidas nessa instituição.

É importante ressaltar que há um desequilíbrio entre o número de viagens atraídas e produzidas entre os turnos das instituições em estudo, conforme mostrado na Figura 7.

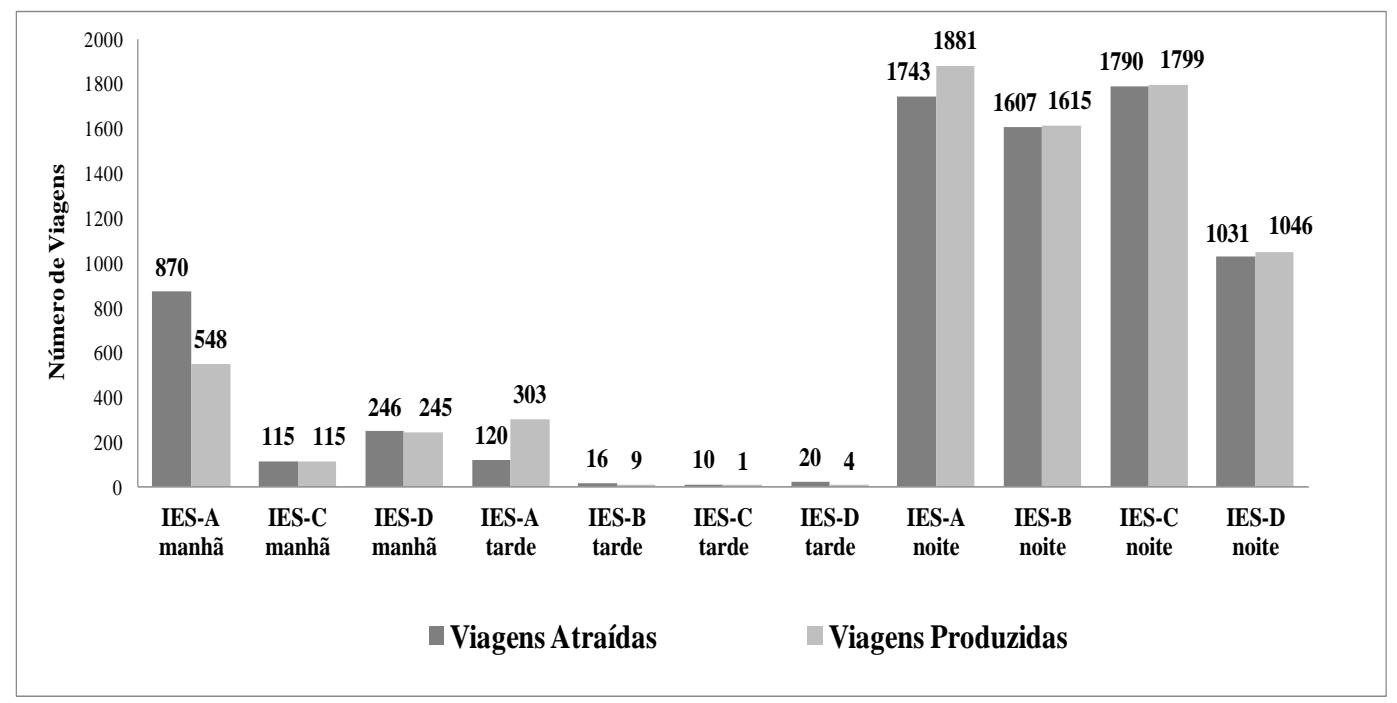

Figura 7 - Total de viagens nos três turnos, ao longo da semana

Observa-se que para o turno da manhã, as viagens atraídas são maiores, ou igual, do que as viagens produzidas para as três instituições. Para os turnos tarde e noite, as viagens produzidas são maiores do que as atraídas para a IES-A, assim como para as IES-B, IES-C e 
IES-D, para o turno da noite. Isso se explica devido à permanência dos alunos na instituição de um turno para outro, ou até mesmo o dia todo, com retorno para casa apenas no turno da noite.

\subsubsection{Modos de transporte}

Nesta seção são apresentadas as porcentagens de viagens para os modos de transporte utilizados pelos alunos nas viagens atraídas e produzidas para as IES pesquisadas. As Figuras 8 e 9 apresentam, respectivamente, essas porcentagens, por turno.

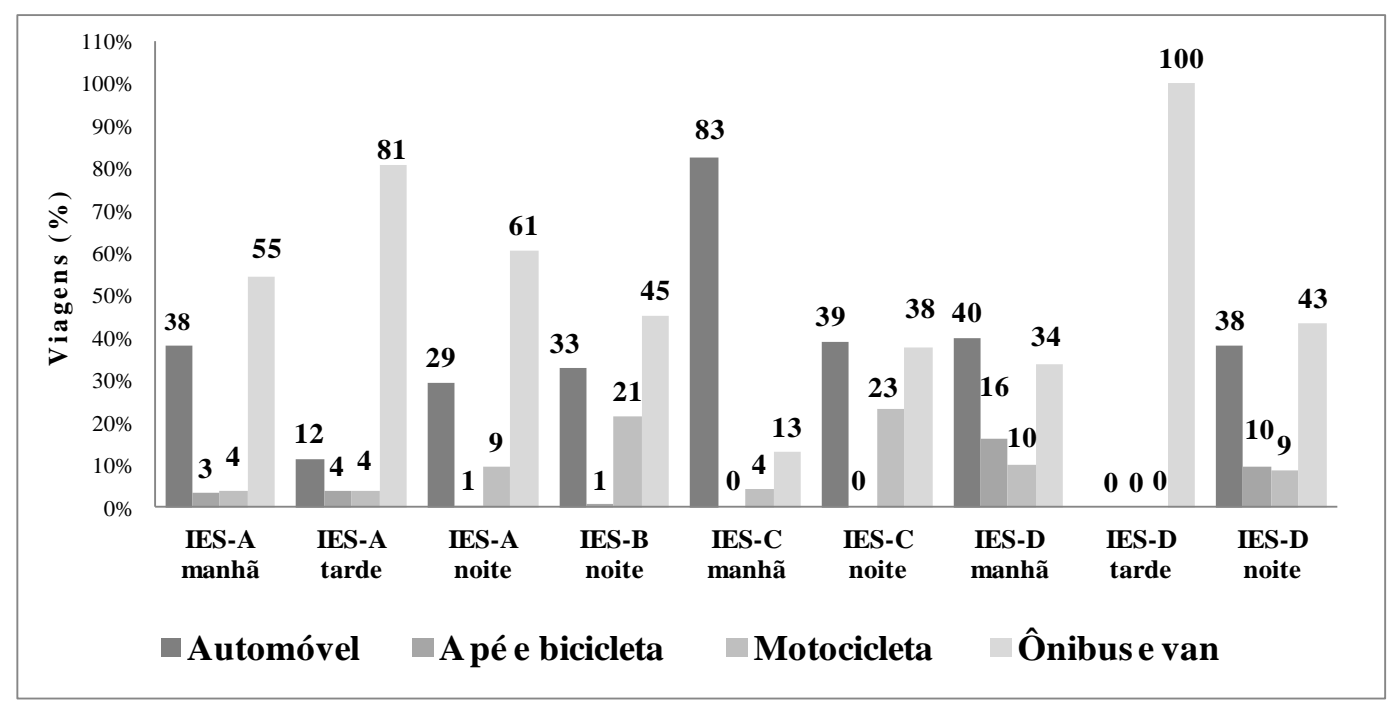

Figura 8 - Modos de transportes utilizados por alunos nas viagens atraídas, por turno

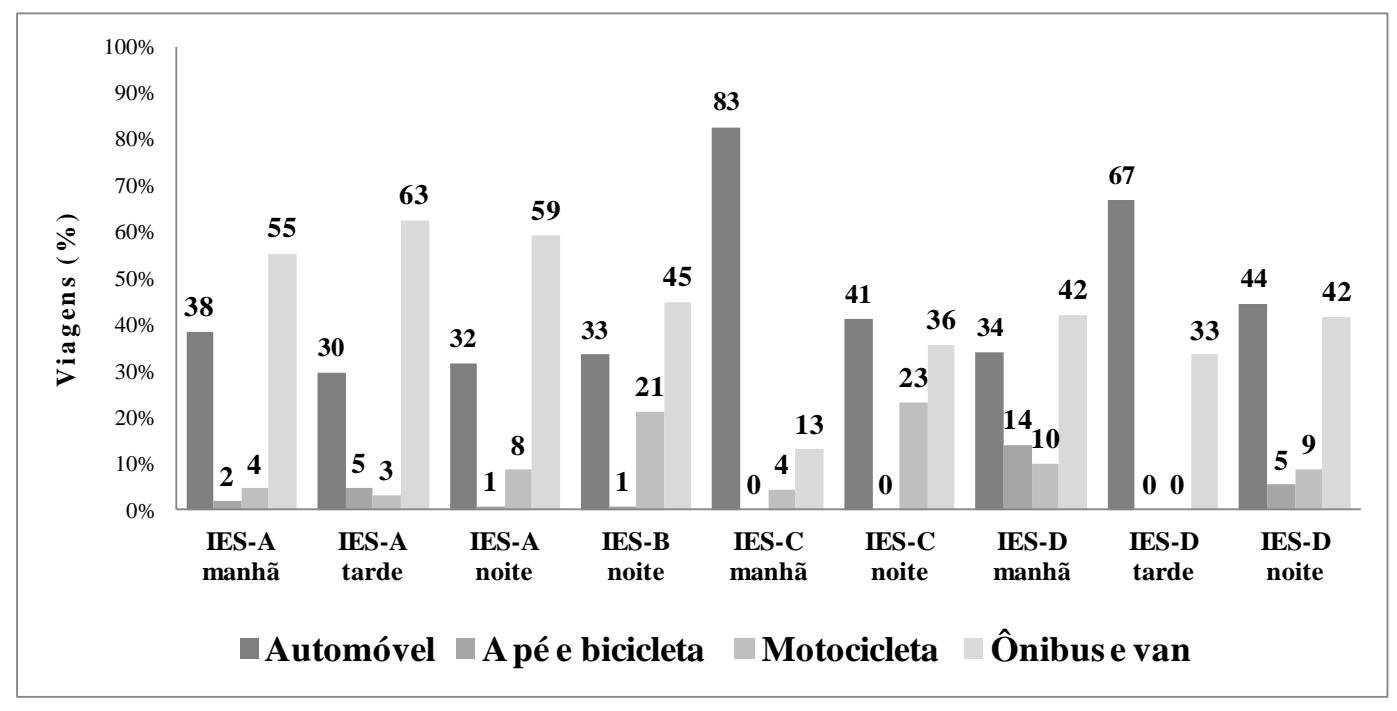

Figura 9 - Modos de transportes utilizados por alunos nas viagens produzidas, por turno 
Com base nos resultados das Figuras 8 e 9, constatou-se que o principal modo de transporte utilizado pelos alunos, tanto nas viagens atraídas como nas produzidas, foi o ônibus e van. A IES-C foi a única instituição que possuiu o automóvel como principal modo de transporte, tanto para as viagens atraídas como para as produzidas.

Foi percebido na IES-D tarde que 100\% das viagens atraídas utilizaram o modo de transporte ônibus e van. Entretanto, na mesma instituição, para as viagens produzidas, apenas 33\% dos usuários utilizaram o mesmo modo de transporte, e o restante, 67\%, utilizaram o automóvel. Essa situação se explica, pelo fato dos alunos saírem da instituição de carona ou alguém buscou, utilizando o automóvel.

Conclui-se, dessa forma, que os alunos vão à instituição de ônibus e retornam de automóvel carona ou automóvel (alguém buscou/levou na instituição). Semelhante situação também acontece com a IES-A tarde, onde os alunos realizam $81 \%$ das viagens atraídas utilizando o modo de transporte ônibus e van, e $12 \%$ utilizando o automóvel. Com relação às viagens produzidas, o percentual de usuários que utilizam o modo de transporte ônibus e van é menor. Em contrapartida, há um aumento no percentual de viagens produzidas que utilizam o automóvel. Sendo assim, pode-se afirmar que os usuários que vão à instituição e utilizam o modo de transporte ônibus retornam ao seu local de destino utilizando outro modo de transporte, o automóvel carona ou o automóvel (alguém levou/buscou na instituição).

No questionário aplicado aos usuários, a última questão perguntava se o usuário possuía o desejo de mudar o modo de transporte utilizado por ele nas viagens atraídas e produzidas, se houvesse possibilidade. Se sim, qual seria esse modo de transporte que ele desejaria utilizar?

Com o objetivo de visualizar a percepção dos usuários quanto ao modo de transporte utilizado em relação àquele desejado, independente de instituição e turno, foram elaboradas as Figuras 10 e 11. Comparando-as verifica-se que os resultados encontrados para as viagens atraídas são semelhantes às produzidas, independente do modo de transporte utilizado. 


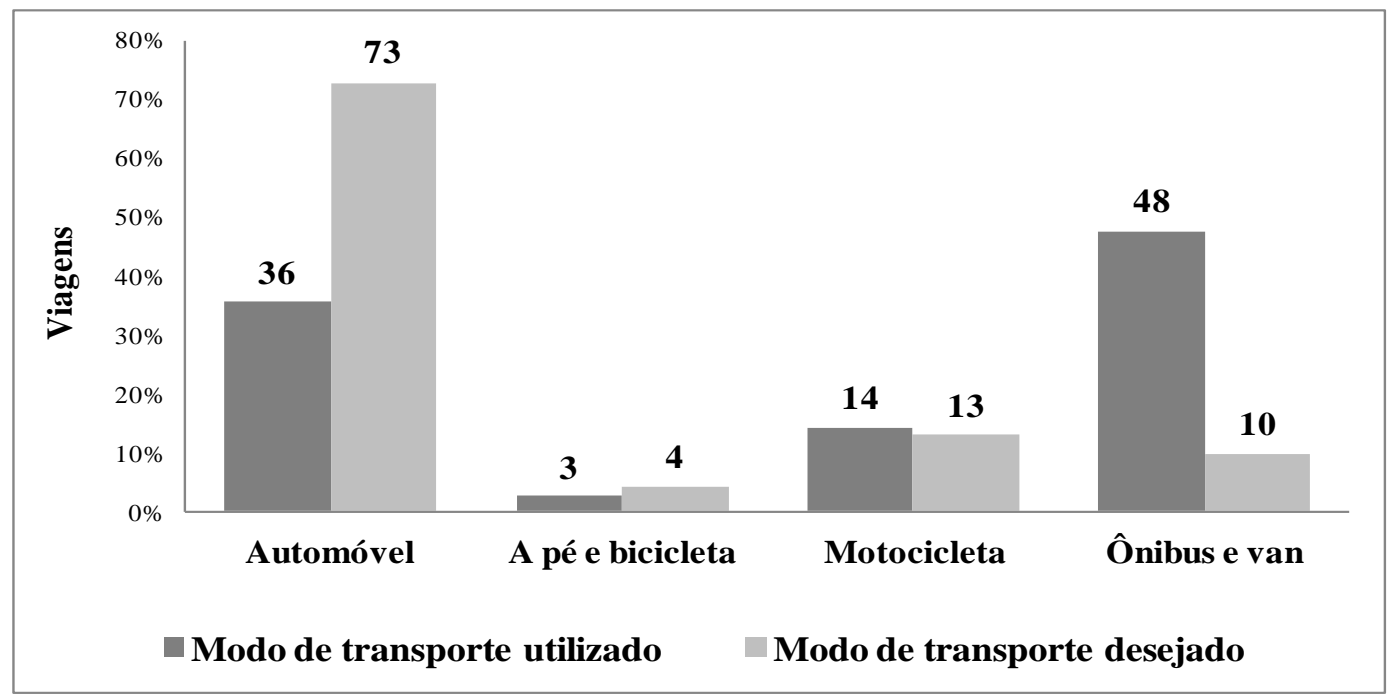

Figura 10 - Comparação entre os modos de transportes utilizados e os desejados pelos alunos de todas as IES, para as viagens atraídas

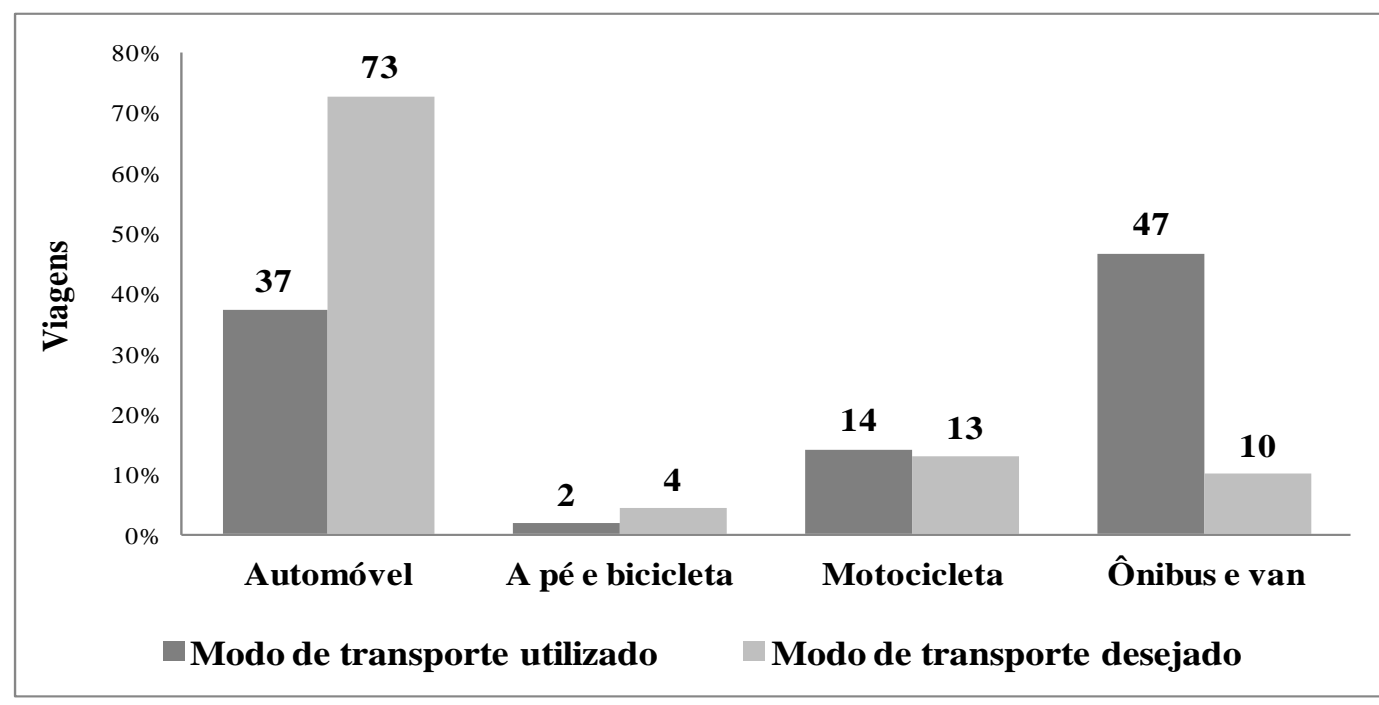

Figura 11 - Comparação entre os modos de transportes utilizados e os desejados pelos alunos de todas as IES, para as viagens produzidas

Quanto ao modo de transporte verifica-se que o modo ônibus e van é utilizado por $48 \%$ dos alunos. Contudo, quando questionados quanto ao modo de transporte desejado, $73 \%$ dos alunos desejaram o modo automóvel. Ressalta-se que desses 73\%, 37\% se referem aos usuários que já utilizam o modo automóvel, os quais não desejaram alterar o seu modo de transporte. Conclui-se, com isso, que o modo de transporte coletivo urbano e interurbano não está atendendo satisfatoriamente os usuários. Para os demais modos de transporte analisados não houve significativa alteração, entre o utilizado e o desejado. 
Percebeu-se que o aumento no modo de transporte automóvel se deu em virtude do desejo dos alunos que utilizam o modo ônibus, principalmente o interurbano, em propiciar viagens mais rápidas e confortáveis à instituição. Outro fator importante observado foi que grande parte dos alunos das instituições privadas utilizam o modo de transporte ônibus (urbano/interurbano), talvez, por não possuírem condição de adquirir um carro.

Observa-se uma leve preferência na troca do modo de transporte para o modo a pé e bicicleta. Isso pode ser explicado pela falta de estrutura adequada e segura para ciclistas e pedestres. Para o modo de transporte motocicleta, constatou-se que, não tiveram um aumento nesse modo de transporte. Com relação ao modo de transporte ônibus e van, observa-se que houve uma redução significativa na preferência de permanência desse modo de transporte. Pode-se concluir que o transporte público urbano e o interurbano têm muito a melhorar na sua oferta e qualidade. Atualmente, o transporte por ônibus é utilizado devido a não possibilidade de os usuários adquirirem um automóvel, apesar da preferência por esse meio.

\subsubsection{Local de origem e destino das viagens}

Nesta seção serão apresentados os resultados obtidos referentes aos locais de origem e destino das viagens realizadas pelos alunos das instituições. Pretende-se identificar se os alunos possuem a residência ou o trabalho como origem/destino das suas viagens às IES. Nas Figuras 12 e 13 são apresentados os percentuais das viagens realizadas pelos alunos, tendo como local de origem e destino, a residência, o trabalho e outro.

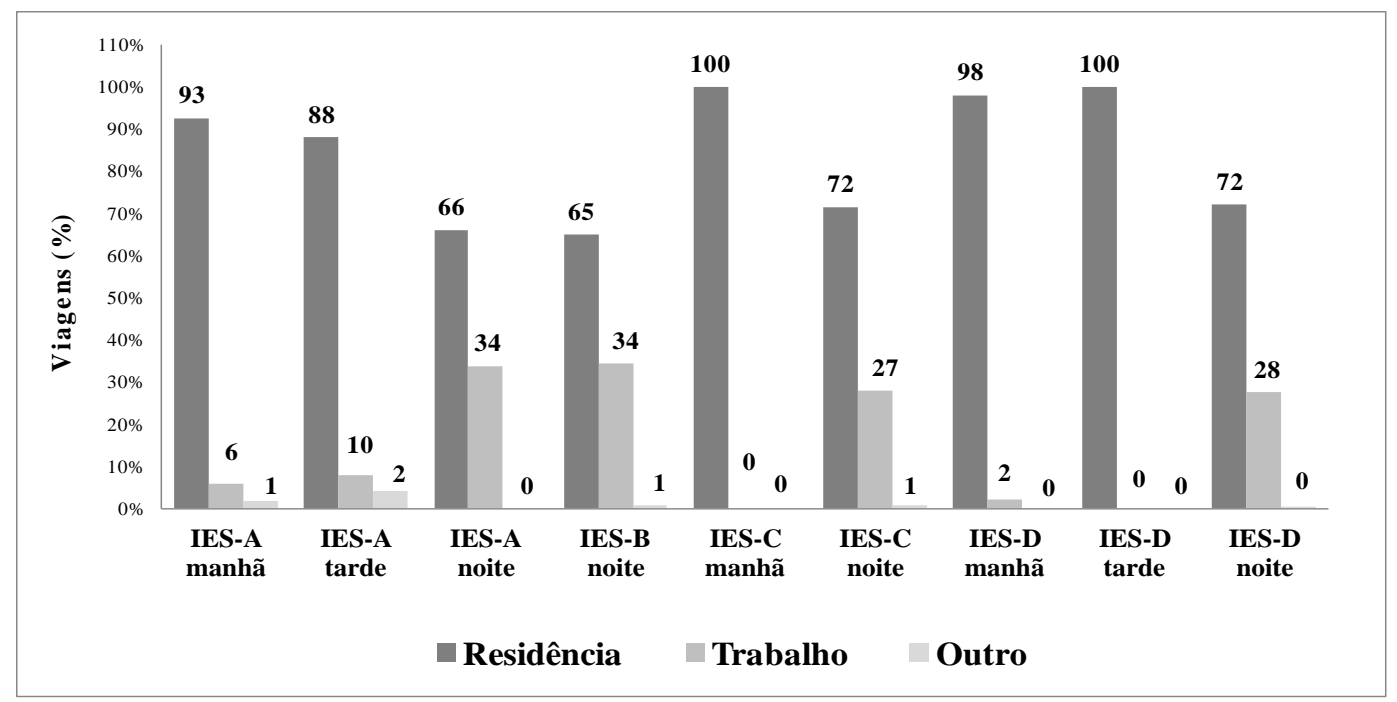

Figura 12 - Local de origem das viagens realizadas pelos alunos 


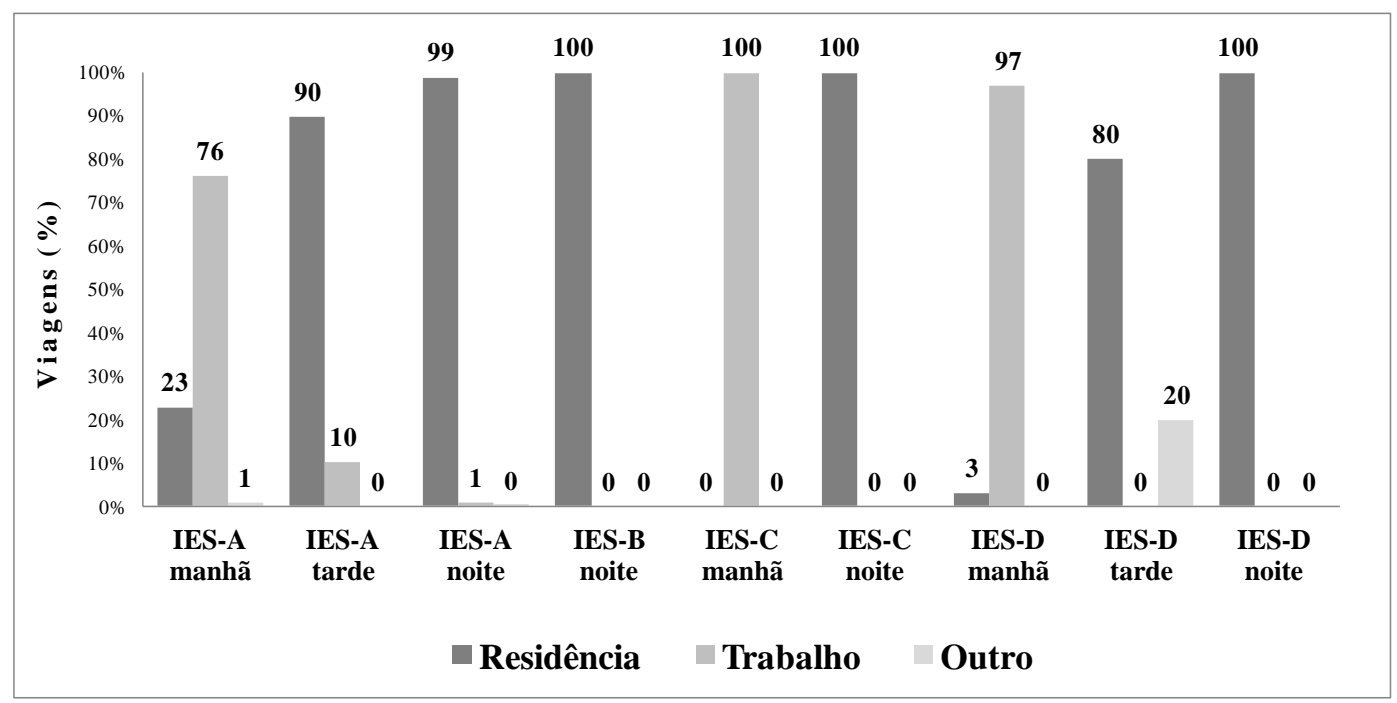

Figura 13 - Local de destino das viagens realizadas pelos alunos

Verifica-se na Figura 12 que a maioria das viagens às instituições realizadas no turno da manhã, IES-A, IES-C e IES-D, tem a sua origem na residência. Com relação ao local de destino das viagens, Figura 13, nota-se, para as mesmas instituições, que o destino das viagens no turno da manhã, em sua maioria é para o trabalho. No caso específico da IES-A verifica-se que $23 \%$ dos alunos retornam às residências ao final do turno.

Para o turno da tarde, a IES-D possui $100 \%$ de viagens originadas das residências. Em contrapartida, para a IES-A, apenas $88 \%$ dos alunos tem a residência como origem das viagens, sendo o restante oriundo do trabalho e outro. Quanto ao local de destino, no turno da tarde, as IES-A e IES-D continuam com predominância à residência, com $90 \%$ e $80 \%$, respectivamente. Ainda com relação à IES-D, turno da tarde, destaca-se o valor de $20 \%$ das viagens com outro destino, que não seja residência ou trabalho.

Quanto ao turno da noite o cenário é um pouco diferente. A maioria dos alunos que estudam no período noturno trabalha durante o dia. Sendo assim, alguns têm como origem da sua viagem o trabalho e alguns alunos conseguem sair do trabalho e passar na sua residência antes de ir para a instituição. As IES-A e IES-B possuem 34\% das viagens originadas do trabalho e quase que o restante da residência. Já as IES-C e IES-D possuem um número menor, entre $27 \%$ e $28 \%$, respectivamente, das viagens têm origem no trabalho e $72 \%$ na residência. Com relação ao local de destino das viagens observa-se que para todas as instituições que possuem o turno da noite, a maioria dos seus alunos têm como destino de suas viagens as residências. 
A partir das análises realizadas constatou-se que o perfil dos alunos que estudam durante o dia é diferente dos que estudam no turno noturno. Para o período diurno, uma minoria de alunos trabalha, sendo assim, a origem das viagens tem predominância na residência. Para o período noturno, boa parte dos alunos trabalha ou faz estágio durante o dia. Além disso, verifica-se também que o destino das viagens é heterogêneo, principalmente no período da manhã, onde alguns alunos saem da instituição e vão diretamente para o trabalho ou estágio.

\subsubsection{Localização física do local de origem e destino das viagens}

O local de origem e destino das viagens realizadas pelos alunos possui uma localização física, ou seja, de qual bairro ou cidade essas viagens se originam. A partir dos resultados da pesquisa observou-se uma heterogeneidade de bairros para as instituições (Tabela 7). Optouse, então, por trabalhar com Setores: Norte, Sul, Central, Leste e Oeste, fornecido pela prefeitura de Uberlândia, onde constam, também, as 65 zonas de tráfegos definidas para a cidade.

Tabela 7 - Bairros por setor territorial

\begin{tabular}{|c|c|}
\hline Setor & Bairro \\
\hline Norte & $\begin{array}{l}\text { Jardim Brasília, Maravilha, Marta Helena, Minas Gerais, Nossa Senhora das Graças, } \\
\text { Pacaembu, Presidente Roosevelt, Residencial Gramado, Santa Rosa e São José. }\end{array}$ \\
\hline Sul & $\begin{array}{l}\text { Carajás, Cidade Jardim, Granada, Jardim Inconfidência, Jardim Karaiba, Lagoinha, } \\
\text { Laranjeiras, Morada da Colina, Nova Uberlândia, Pampulha, Patrimônio, Santa Luiza, São } \\
\text { Jorge, Saraiva, Shopping Parque, Tubalina e Vigilato Pereira. }\end{array}$ \\
\hline Central & $\begin{array}{l}\text { Bom Jesus, Brasil, Cazeca, Centro, Daniel Fonseca, Lídice, Martins, Nossa Senhora } \\
\text { Aparecida, Osvaldo Rezende e Tabajaras. }\end{array}$ \\
\hline Leste & $\begin{array}{l}\text { Alto Umuarama, Custódio Pereira, Jardim Ipanema, Morada dos Pássaros, Morumbi, } \\
\text { Santa Mônica, Segismundo Pereira, Tibery e Umuarama. }\end{array}$ \\
\hline Oeste & $\begin{array}{l}\text { Chácaras Tubalina e Quartel, Dona Zulmira, Guarani, Jaraguá, Jardim Canaã, Jardim das } \\
\text { Palmeiras, Jardim Europa, Jardim Holanda, Jardim Patrícia, Luizote de Freitas, Mansour, } \\
\text { Morada do Sol, Panorama, Planalto, Taiaman, Tocantins. }\end{array}$ \\
\hline
\end{tabular}

Fonte: UBERLÂNDIA (2012)

Na Tabela 8 são mostrados os valores diários coletados e percentuais dos locais de origem e destino das viagens realizadas pelos alunos da IES-A, em função dos setores da cidade. 
Tabela 8 - Valores diários e percentuais dos locais de origem e destino das viagens realizadas pelos alunos da IES-A, em função dos setores da cidade

\begin{tabular}{|c|c|c|c|c|c|c|c|c|}
\hline \multirow{2}{*}{$\begin{array}{c}\text { Instituição/ } \\
\text { turno }\end{array}$} & \multicolumn{4}{|c|}{ Origem das viagens } & \multicolumn{4}{|c|}{ Destino das viagens } \\
\hline & Local* & Setor & $\begin{array}{l}\text { Valores } \\
\text { diários }\end{array}$ & $\%$ & Local* & Setor & $\begin{array}{l}\text { Valores } \\
\text { diários }\end{array}$ & $\%$ \\
\hline \multirow{14}{*}{ IES-A manhã } & & Norte & 25 & 15,3 & \multirow{6}{*}{$\begin{array}{c}\text { Residência } \\
23 \%\end{array}$} & Norte & 4 & 16,0 \\
\hline & & Sul & 22 & 13,5 & & Sul & 3 & 12,0 \\
\hline & Residência & Central & 47 & 28,8 & & Central & 6 & 24,0 \\
\hline & $93 \%$ & Leste & 43 & 26,4 & & Leste & 5 & 20,0 \\
\hline & & Oeste & 18 & 11,0 & & Oeste & 6 & 24,0 \\
\hline & & Outro & 8 & 4,9 & & Outro & 1 & 7,0 \\
\hline & \multicolumn{2}{|c|}{ Total } & 163 & 100,0 & \multicolumn{2}{|c|}{ Total } & 25 & 100,0 \\
\hline & \multirow{6}{*}{$\begin{array}{c}\text { Trabalho } \\
6 \%\end{array}$} & Norte & 1 & 10,0 & \multirow{6}{*}{$\begin{array}{c}\text { Trabalho } \\
76 \%\end{array}$} & Norte & 13 & 15,7 \\
\hline & & Sul & 2 & 20,0 & & Sul & 10 & 12,0 \\
\hline & & Central & 0 & 0,0 & & Central & 15 & 18,1 \\
\hline & & Leste & 6 & 60,0 & & Leste & 30 & 36,1 \\
\hline & & Oeste & 1 & 10,0 & & Oeste & 10 & 12,0 \\
\hline & & Outro & 0 & 0,0 & & Outro & 5 & 6,0 \\
\hline & \multicolumn{2}{|c|}{ Total } & 10 & 100,0 & \multicolumn{2}{|c|}{ Total } & 83 & 100,0 \\
\hline \multirow{14}{*}{ IES-A tarde } & \multirow{6}{*}{$\begin{array}{c}\text { Residência } \\
88 \%\end{array}$} & Norte & 1 & 3,6 & \multirow{6}{*}{$\begin{array}{c}\text { Residência } \\
90 \%\end{array}$} & Norte & 9 & 12,9 \\
\hline & & Sul & 5 & 17,9 & & Sul & 11 & 15,7 \\
\hline & & Central & 3 & 10,7 & & Central & 22 & 31,4 \\
\hline & & Leste & 9 & 32,1 & & Leste & 14 & 20,0 \\
\hline & & Oeste & 2 & 7,1 & & Oeste & 11 & 15,7 \\
\hline & & Outro & 8 & 28,6 & & Outro & 3 & 4,3 \\
\hline & \multicolumn{2}{|c|}{ Total } & 28 & 100,0 & \multicolumn{2}{|c|}{ Total } & 70 & 100,0 \\
\hline & \multirow{6}{*}{$\begin{array}{c}\text { Trabalho } \\
10 \%\end{array}$} & Norte & 1 & 50,0 & \multirow{6}{*}{$\begin{array}{c}\text { Trabalho } \\
10 \%\end{array}$} & Norte & 1 & 12,5 \\
\hline & & Sul & 0 & 0,0 & & Sul & 3 & 37,5 \\
\hline & & Central & 0 & 0,0 & & Central & 1 & 12,5 \\
\hline & & Leste & 1 & 50,0 & & Leste & 2 & 25,0 \\
\hline & & Oeste & 0 & 0,0 & & Oeste & 0 & 0,0 \\
\hline & & Outro & 0 & 0,0 & & Outro & 1 & 12,5 \\
\hline & \multicolumn{2}{|c|}{ Total } & 2 & 100,0 & \multicolumn{2}{|c|}{ Total } & 8 & 100,0 \\
\hline \multirow{14}{*}{ IES-A noite } & \multirow{6}{*}{$\begin{array}{c}\text { Residência } \\
66 \%\end{array}$} & Norte & 36 & 15,6 & \multirow{6}{*}{$\begin{array}{c}\text { Residência } \\
99 \%\end{array}$} & Norte & 52 & 14,5 \\
\hline & & Sul & 41 & 17,7 & & Sul & 61 & 17,0 \\
\hline & & Central & 24 & 10,4 & & Central & 37 & 10,3 \\
\hline & & Leste & 57 & 24,7 & & Leste & 92 & 25,7 \\
\hline & & Oeste & 29 & 12,6 & & Oeste & 52 & 14,5 \\
\hline & & Outro & 44 & 19,0 & & Outro & 64 & 17,9 \\
\hline & To & & 231 & 100,0 & To & & 358 & 100,0 \\
\hline & & Norte & 17 & 14,9 & & Norte & 0 & 0,0 \\
\hline & & Sul & 18 & 15,8 & & Sul & 2 & 66,7 \\
\hline & Trabalho & Central & 14 & 12,3 & Trabalho & Central & 1 & 33,3 \\
\hline & $34 \%$ & Leste & 34 & 29,8 & $1 \%$ & Leste & 0 & 0,0 \\
\hline & & Oeste & 18 & 15,8 & & Oeste & 0 & 0,0 \\
\hline & & Outro & 13 & 11,4 & & Outro & 0 & 0,0 \\
\hline & To & & 114 & 100,0 & To & & 3 & 100,0 \\
\hline
\end{tabular}

* Para algumas IES o percentual do local de origem e destino das viagens, distribuído entre a residência e o trabalho, não alcança 100\%. Essa condição se deve ao fato de que alguns alunos assinalaram a opção "Outro" na questão número 9 do questionário. Entendem-se como "Outro" locais como estágios, eventos festivos, cursos etc. 
Nota-se, para o turno da manhã, que para as viagens com origem na residência a maioria provém dos setores Central e Leste, com 28,8\% e 26,4\%, respectivamente. Verificaram-se, nas respostas dos questionários, que 4,9\% das viagens são originadas em outras localidades, tais como, cidades vizinhas e distritos de Uberlândia. Quando se analisa a residência como local de destino das viagens verifica-se um percentual maior para os setores Central e Oeste. Quando se considera o local de origem como sendo o trabalho, constata-se que a maioria das viagens provém da zona Leste. Contudo, deve-se considerar a baixa quantidade de alunos que têm sua viagem originada no trabalho neste turno (somente 10 alunos). Com relação ao local de destino das viagens nota-se, na Tabela 8 , que a grande maioria das viagens $(36,1 \%)$ tem como destino o setor Leste no turno da manhã.

Para o turno da tarde observa-se que a maioria das viagens que chegam à instituição IES-A tem sua origem em residências localizadas nos setores Leste $(32,1 \%)$ e Sul (17,9\%), conforme Tabela 8. Deve-se destacar o considerável percentual $(28,6 \%)$ de viagens oriundas de residências das cidades vizinhas e distritos de Uberlândia.

Para as viagens com origem no trabalho a mesma analogia da IES-A turno da manhã pode ser aplicada para o turno da tarde, ou seja, apesar de ter-se observado viagens partindo de bairros localizados nos setores Leste e Norte somente, é imperativo considerar a baixa quantidade (2 respondentes apenas) de alunos que informaram ter sua viagem originada no trabalho neste turno. Quando se analisa o destino das viagens como sendo a residência verifica-se que a maioria tem como destino os setores Central e Leste, com percentuais de 31,4 e 20,0, respectivamente. Para as viagens com destino ao trabalho verifica-se que 37,5\% das mesmas tem como destino o setor Sul, seguido pelo setor Leste, com $25 \%$.

Ao analisar o turno noturno na IES-A (Tabela 8) verifica-se uma distribuição homogênea entre os setores para as viagens oriundas da residência e do trabalho, com ligeiro destaque ao setor Leste, onde foi verificado que $24,7 \%$ e $29,8 \%$ das viagens tiveram sua origem na residência e no trabalho, respectivamente. Quanto ao local de destino das viagens observa-se que $26,4 \%$, de um total de $99 \%$, têm como destino as residências localizadas no setor Leste. Por outro lado, quando se analisa o trabalho como destino das viagens observa-se predominância para os setores Sul e Central, porém, somente 1\% dos usuários informou que o seu destino, após sair da instituição no turno noturno, é o trabalho. 
Os valores diários coletados e os percentuais dos locais de origem e destino das viagens realizadas pelos alunos da IES-B turno da noite, são mostrados na Tabela 9. Nota-se que as viagens com origem na residência estão concentradas no setor Leste $(36,2 \%)$ e Sul $(21,3)$. Quando se analisa a origem da viagem como sendo do trabalho constata-se uma concentração nos setores Leste e Central, com percentuais de 28,6 e 21,0, respectivamente. Quanto ao local de destino das viagens observa-se que $100 \%$ das viagens que tem como destino as residências, $35,7 \%$ se concentram no setor Leste e $20,2 \%$ no setor Sul. Não foram verificadas viagens com destino ao trabalho.

Tabela 9 - Valores diários e percentuais dos locais de origem e destino das viagens realizadas pelos alunos da IES-B, em função dos setores da cidade.

\begin{tabular}{|c|c|c|c|c|c|c|c|c|}
\hline \multirow[b]{2}{*}{ Instituição } & \multicolumn{4}{|c|}{ Origem das viagens } & \multicolumn{4}{|c|}{ Destino das viagens } \\
\hline & Local* & Setor & $\begin{array}{l}\text { Valores } \\
\text { diários }\end{array}$ & $\%$ & Local* & Setor & $\begin{array}{l}\text { Valores } \\
\text { diários }\end{array}$ & $\%$ \\
\hline \multirow{14}{*}{ IES-B noite } & \multirow{6}{*}{$\begin{array}{c}\text { Residência } \\
65 \%\end{array}$} & Norte & 29 & 14,0 & \multirow{6}{*}{$\begin{array}{c}\text { Residência } \\
100 \%\end{array}$} & Norte & 45 & 14,0 \\
\hline & & Sul & 44 & 21,3 & & Sul & 65 & 20,2 \\
\hline & & Central & 20 & 9,7 & & Central & 35 & 10,9 \\
\hline & & Leste & 75 & 36,2 & & Leste & 115 & 35,7 \\
\hline & & Oeste & 26 & 12,6 & & Oeste & 38 & 11,8 \\
\hline & & Outro & 13 & 6,3 & & Outro & 24 & 7,5 \\
\hline & \multicolumn{2}{|c|}{ Total } & 207 & 100,0 & \multicolumn{2}{|c|}{ Total } & 322 & 100,0 \\
\hline & \multirow{6}{*}{$\begin{array}{c}\text { Trabalho } \\
34 \%\end{array}$} & Norte & 16 & 15,2 & \multirow{6}{*}{$\begin{array}{c}\text { Trabalho } \\
0 \%\end{array}$} & Norte & 0 & 0,0 \\
\hline & & Sul & 12 & 11,4 & & Sul & 0 & 0,0 \\
\hline & & Central & 22 & 21,0 & & Central & 0 & 0,0 \\
\hline & & Leste & 30 & 28,6 & & Leste & 0 & 0,0 \\
\hline & & Oeste & 13 & 12,4 & & Oeste & 0 & 0,0 \\
\hline & & Outro & 12 & 11,4 & & Outro & 0 & 0,0 \\
\hline & \multicolumn{2}{|c|}{ Total } & 105 & 100,0 & \multicolumn{2}{|c|}{ Total } & 0 & 0,0 \\
\hline
\end{tabular}

* Para algumas IES o percentual do local de origem e destino das viagens, distribuído entre a residência e o trabalho, não alcança 100\%. Essa condição se deve ao fato de que alguns alunos assinalaram a opção "Outro" na questão número 9 do questionário. Entendem-se como "Outro" locais como estágios, eventos festivos, cursos etc.

Os valores diários e percentuais dos locais de origem e destino das viagens realizadas pelos alunos da IES-C, nos turnos da manhã e noite, são mostrados, na Tabela 10. Observa-se, para o turno da manhã, que, para as viagens com origem na residência, a maioria provém dos setors Leste, Central e Norte, com 30,4\%, 26,1\% e 21,7\%, respectivamente. Em contrapartida, quando se analisa a residência como local de destino das viagens, verifica-se que nenhum usuário retorna à mesma, ou seja, todos têm como destino o trabalho. Situação semelhante se verifica para as viagens com origem no trabalho, ou seja, nenhum aluno sai do trabalho e se desloca diretamente para instituição de ensino. Por outro lado, quando se considera o local de destino como sendo o trabalho, constata-se que a maioria das viagens tem como destino os setores Central e Leste. 
Para o turno noturno da IES-C (Tabela 10) observa-se uma predominância das viagens oriundas de residências localizadas no setor Oeste $(33,7 \%)$. Para as viagens com origem no trabalho destaca-se o setor Sul, com 37,2\%, seguida pelos setores Leste e Oeste, ambas com $22,3 \%$. Com relação ao local de destino das viagens observa-se que $26,5 \%$, de um total de $100 \%$, têm como destino as residências localizadas no setor Leste. Não foram verificadas viagens com destino ao trabalho, indicando que todos os alunos, após saírem da instituição, têm como destino a residência.

Tabela 10 - Valores diários e percentuais dos locais de origem e destino das viagens realizadas pelos alunos da IES-C, em função dos setores da cidade.

\begin{tabular}{|c|c|c|c|c|c|c|c|c|}
\hline \multirow[b]{2}{*}{ Instituição } & \multicolumn{4}{|c|}{ Origem das viagens } & \multicolumn{4}{|c|}{ Destino das viagens } \\
\hline & Local* & Setor & $\begin{array}{l}\text { Valores } \\
\text { diários }\end{array}$ & $\%$ & Local* & Setor & $\begin{array}{l}\text { Valores } \\
\text { diários }\end{array}$ & $\%$ \\
\hline \multirow{14}{*}{$\begin{array}{l}\text { IES-C } \\
\text { manhã }\end{array}$} & \multirow{6}{*}{$\begin{array}{c}\text { Residência } \\
100 \%\end{array}$} & Norte & 5 & 21,7 & \multirow{6}{*}{$\begin{array}{c}\text { Residência } \\
0 \%\end{array}$} & Norte & 0 & 0,0 \\
\hline & & Sul & 1 & 4,3 & & Sul & 0 & 0,0 \\
\hline & & Central & 6 & 26,1 & & Central & 0 & 0,0 \\
\hline & & Leste & 7 & 30,4 & & Leste & 0 & 0,0 \\
\hline & & Oeste & 4 & 17,4 & & Oeste & 0 & 0,0 \\
\hline & & Outro & 0 & 0,0 & & Outro & 0 & 0,0 \\
\hline & \multicolumn{2}{|c|}{ Total } & 23 & 100,0 & \multicolumn{2}{|c|}{ Total } & 0 & 0,0 \\
\hline & \multirow{6}{*}{$\begin{array}{c}\text { Trabalho } \\
0 \%\end{array}$} & Norte & 0 & 0,0 & \multirow{6}{*}{$\begin{array}{c}\text { Trabalho } \\
100 \%\end{array}$} & Norte & 1 & 5,6 \\
\hline & & Sul & 0 & 0,0 & & Sul & 3 & 16,7 \\
\hline & & Central & 0 & 0,0 & & Central & 7 & 38,9 \\
\hline & & Leste & 0 & 0,0 & & Leste & 5 & 27,8 \\
\hline & & Oeste & 0 & 0,0 & & Oeste & 1 & 5,6 \\
\hline & & Outro & 0 & 0,0 & & Outro & 1 & 5,6 \\
\hline & \multicolumn{2}{|c|}{ Total } & 0 & 0,0 & \multicolumn{2}{|c|}{ Total } & 18 & 100,0 \\
\hline \multirow{14}{*}{ IES-C noite } & & Norte & 30 & 12,3 & \multirow{6}{*}{$\begin{array}{c}\text { Residência } \\
100 \%\end{array}$} & Norte & 70 & 19,1 \\
\hline & & Sul & 48 & 19,8 & & Sul & 68 & 18,6 \\
\hline & Residência & Central & 16 & 6,6 & & Central & 34 & 9,3 \\
\hline & $72 \%$ & Leste & 48 & 19,8 & & Leste & 97 & 26,5 \\
\hline & & Oeste & 82 & 33,7 & & Oeste & 66 & 18,0 \\
\hline & & Outro & 19 & 7,8 & & Outro & 31 & 8,5 \\
\hline & \multicolumn{2}{|c|}{ Total } & 243 & 100,0 & \multicolumn{2}{|c|}{ Total } & 366 & 100,0 \\
\hline & \multirow{6}{*}{$\begin{array}{c}\text { Trabalho } \\
27 \%\end{array}$} & Norte & 9 & 9,6 & \multirow{6}{*}{$\begin{array}{c}\text { Trabalho } \\
0 \%\end{array}$} & Norte & 0 & 0,0 \\
\hline & & Sul & 35 & 37,2 & & Sul & 0 & 0,0 \\
\hline & & Central & 5 & 5,3 & & Central & 0 & 0,0 \\
\hline & & Leste & 21 & 22,3 & & Leste & 0 & 0,0 \\
\hline & & Oeste & 21 & 22,3 & & Oeste & 0 & 0,0 \\
\hline & & Outro & 3 & 3,2 & & Outro & 0 & 0,0 \\
\hline & \multicolumn{2}{|c|}{ Total } & 94 & 100,0 & \multicolumn{2}{|c|}{ Total } & 0 & 0,0 \\
\hline
\end{tabular}

* Para algumas IES o percentual do local de origem e destino das viagens, distribuído entre a residência e o trabalho, não alcança 100\%. Essa condição se deve ao fato de que alguns alunos assinalaram a opção "Outro" na questão número 9 do questionário. Entendem-se como "Outro" locais como estágios, eventos festivos, cursos etc.

Os valores diários coletados e percentuais dos locais de origem e destino das viagens realizadas pelos alunos da IES-D turnos da manhã, tarde e noite, em função dos setores da cidade, são mostrados na Tabela 11. 
Tabela 11 - Valores diários e percentuais dos locais de origem e destino das viagens realizadas pelos alunos da IES-D, em função dos setores da cidade.

\begin{tabular}{|c|c|c|c|c|c|c|c|c|}
\hline \multirow[b]{2}{*}{ Instituição } & \multicolumn{4}{|c|}{ Origem das viagens } & \multicolumn{4}{|c|}{ Destino das viagens } \\
\hline & Local* & Setor & $\begin{array}{l}\text { Valores } \\
\text { diários }\end{array}$ & $\%$ & Local* & Setor & $\begin{array}{l}\text { Valores } \\
\text { diários }\end{array}$ & $\%$ \\
\hline \multirow{14}{*}{$\begin{array}{l}\text { IES-D } \\
\text { manhã }\end{array}$} & & Norte & 9 & 20,5 & \multirow{6}{*}{$\begin{array}{c}\text { Residência } \\
3 \%\end{array}$} & Norte & 0 & 0,0 \\
\hline & & Sul & 2 & 4,5 & & Sul & 0 & 0,0 \\
\hline & Residência & Central & 10 & 22,7 & & Central & 1 & 100,0 \\
\hline & $98 \%$ & Leste & 8 & 18,2 & & Leste & 0 & 0,0 \\
\hline & & Oeste & 15 & 34,1 & & Oeste & 0 & 0,0 \\
\hline & & Outro & 0 & 0,0 & & Outro & 0 & 0,0 \\
\hline & \multicolumn{2}{|c|}{ Total } & 44 & 100,0 & \multicolumn{2}{|c|}{ Total } & 1 & 100,0 \\
\hline & \multirow{6}{*}{$\begin{array}{c}\text { Trabalho } \\
2 \%\end{array}$} & Norte & 0 & 0,0 & \multirow{6}{*}{$\begin{array}{c}\text { Trabalho } \\
97 \%\end{array}$} & Norte & 1 & 3,2 \\
\hline & & Sul & 0 & 0,0 & & Sul & 0 & 0,0 \\
\hline & & Central & 0 & 0,0 & & Central & 13 & 41,9 \\
\hline & & Leste & 0 & 0,0 & & Leste & 6 & 19,4 \\
\hline & & Oeste & 1 & 100,0 & & Oeste & 11 & 35,5 \\
\hline & & Outro & 0 & 0,0 & & Outro & 0 & 0,0 \\
\hline & \multicolumn{2}{|c|}{ Total } & 1 & 100,0 & \multicolumn{2}{|c|}{ Total } & 31 & 100,0 \\
\hline \multirow{14}{*}{ IES-D tarde } & \multirow{6}{*}{$\begin{array}{c}\text { Residência } \\
100 \%\end{array}$} & Norte & 0 & 0,0 & \multirow{6}{*}{$\begin{array}{c}\text { Residência } \\
80 \%\end{array}$} & Norte & 1 & 25,0 \\
\hline & & Sul & 1 & 25,0 & & Sul & 1 & 25,0 \\
\hline & & Central & 0 & 0,0 & & Central & 1 & 25,0 \\
\hline & & Leste & 0 & 0,0 & & Leste & 0 & 0,0 \\
\hline & & Oeste & 0 & 0,0 & & Oeste & 1 & 25,0 \\
\hline & & Outro & 3 & 75,0 & & Outro & 0 & 0,0 \\
\hline & \multicolumn{2}{|c|}{ Total } & 4 & 100,0 & \multicolumn{2}{|c|}{ Total } & 4 & 100,0 \\
\hline & \multirow{6}{*}{$\begin{array}{c}\text { Trabalho } \\
0 \%\end{array}$} & Norte & 0 & 0,0 & \multirow{6}{*}{$\begin{array}{c}\text { Trabalho } \\
0 \%\end{array}$} & Norte & 0 & 0,0 \\
\hline & & Sul & 0 & 0,0 & & Sul & 0 & 0,0 \\
\hline & & Central & 0 & 0,0 & & Central & 0 & 0,0 \\
\hline & & Leste & 0 & 0,0 & & Leste & 0 & 0,0 \\
\hline & & Oeste & 0 & 0,0 & & Oeste & 0 & 0,0 \\
\hline & & Outro & 0 & 0,0 & & Outro & 0 & 0,0 \\
\hline & \multicolumn{2}{|c|}{ Total } & 0 & 0,0 & \multicolumn{2}{|c|}{0,0} & 0 & 0,0 \\
\hline \multirow{14}{*}{ IES-D noite } & & Norte & 33 & 23,9 & \multirow{6}{*}{$\begin{array}{c}\text { Residência } \\
100 \%\end{array}$} & Norte & 51 & 22,8 \\
\hline & & Sul & 18 & 13,0 & & Sul & 30 & 13,4 \\
\hline & Residência & Central & 22 & 15,9 & & Central & 31 & 13,8 \\
\hline & $72 \%$ & Leste & 23 & 16,7 & & Leste & 35 & 15,6 \\
\hline & & Oeste & 34 & 24,6 & & Oeste & 61 & 27,2 \\
\hline & & Outro & 8 & 5,8 & & Outro & 16 & 7,1 \\
\hline & \multicolumn{2}{|c|}{ Total } & 138 & 100,0 & To & & 224 & 100,0 \\
\hline & & Norte & 7 & 14,0 & & Norte & 0 & 0,0 \\
\hline & & Sul & 8 & 16,0 & & Sul & 0 & 0,0 \\
\hline & Trabalho & Central & 13 & 26,0 & Trabalho & Central & 0 & 0,0 \\
\hline & $28 \%$ & Leste & 9 & 18,0 & $0 \%$ & Leste & 0 & 0,0 \\
\hline & & Oeste & 11 & 22,0 & & Oeste & 0 & 0,0 \\
\hline & & Outro & 2 & 4,0 & & Outro & 0 & 0,0 \\
\hline & To & & 50 & 100,0 & To & & 0 & 0,0 \\
\hline
\end{tabular}

* Para algumas IES o percentual do local de origem e destino das viagens, distribuído entre a residência e o trabalho, não alcança $100 \%$. Essa condição se deve ao fato de que alguns alunos assinalaram a opção "Outro" na questão número 9 do questionário. Entendem-se como "Outro" locais como estágios, eventos festivos, cursos etc.

Observa-se, na Tabela 11, para o turno da manhã, que, para as viagens com origem na residência, a maioria provém dos setores Oeste e Central, com 34,1\% e 22,7\%, 
respectivamente. Quando se considera o local de origem como sendo o trabalho constata-se que $100 \%$ são oriundas do setor Oeste. Contudo, deve-se considerar a baixa quantidade de alunos que têm sua viagem originada no trabalho neste período (somente $2 \%$ do total). A mesma analogia pode ser feita para as viagens que têm como destino as residências, onde se observa que $100 \%$ têm como destino o setor Central. Em contrapartida, quando se analisa o trabalho como local de destino das viagens no turno da manhã verifica-se um percentual maior para os setores Central $(41,9 \%)$ e Oeste $(35,5 \%)$.

Quanto ao turno da tarde observa-se que $100 \%$ das viagens que chegam à instituição de ensino têm sua origem em residências localizadas no setor Sul, com 25,0\%. O restante $(75,0 \%)$ têm sua origem nas cidades vizinhas e distritos de Uberlândia. Porém, deve-se destacar que somente 3 alunos assinalaram que sua viagem tem origem na residência neste turno, sendo um deles do setor Sul e o restante das cidades vizinhas e distritos de Uberlândia. Não foram verificadas viagens com origem no trabalho, indicando que todos os alunos fazem viagens que originam em suas residências. Quando se analisa o destino das viagens como sendo a residência verifica-se uma homogeneidade entre os setores Norte, Sul, Central e Oeste, com valores de $25,0 \%$ cada. Não foram verificadas viagens com destino ao trabalho.

Ao analisar o turno noturno da IES-D (Tabela 11) observa-se uma predominância das viagens oriundas de residências localizadas no setor Oeste, com 24,6\%, e Norte, com 23,9\%. Para as viagens com origem no trabalho destacam-se o setor Central, seguido pelo setor Oeste, ambas com $26,0 \%$ e 22,0\%, respectivamente. Com relação ao local de destino das viagens observa-se que $27,2 \%$ e $22,8 \%$, de um total de $100 \%$, têm como destino as residências localizadas nos setores Oeste e Norte, respectivamente. Não foram verificadas viagens com destino ao trabalho indicando que todos os alunos, após saírem da instituição, têm como destino a residência.

\subsubsection{Tempo de viagem}

Por meio do questionário aplicado nas IES foi permitido obter o tempo que o usuário gasta na ida e na volta à instituição, em função do modo de transporte utilizado, conforme mostrado nas Tabelas 12 e 13. 
Tabela 12 - Tempo gasto pelos alunos nas viagens atraídas para os principais modos de transporte

\begin{tabular}{|c|c|c|c|c|c|c|c|c|c|}
\hline \multirow[t]{2}{*}{ Instituição } & \multirow{2}{*}{$\begin{array}{c}\text { Modo de } \\
\text { Transporte }\end{array}$} & \multicolumn{2}{|c|}{$\begin{array}{l}\text { Viagens } \\
\text { Atraídas* }\end{array}$} & \multicolumn{6}{|c|}{$\begin{array}{l}\text { Percentuais do tempo de viagem em função do modo } \\
\text { de transporte }(\%)\end{array}$} \\
\hline & & Número & $(\%)$ & $<15$ & 15 a 30 & 31 a 45 & 46 a 60 & $>60$ & Total \\
\hline \multirow{5}{*}{$\begin{array}{l}\text { IES-A } \\
\text { manhã }\end{array}$} & Automóvel & 67 & 37,6 & 67,2 & 31,3 & 1,5 & 0,0 & 0,0 & 100 \\
\hline & $\begin{array}{l}\text { A pé e } \\
\text { bicicleta }\end{array}$ & 6 & 3,4 & 83,3 & 16,7 & 0,0 & 0,0 & 0,0 & 100 \\
\hline & Motocicleta & 7 & 3,9 & 42,9 & 57,1 & 0,0 & 0,0 & 0,0 & 100 \\
\hline & Ônibus e van & 98 & 55,1 & 10,2 & 31,6 & 26,5 & 19,4 & 12,2 & 100 \\
\hline & Total & 178 & 100 & & & & & & \\
\hline \multirow{5}{*}{ IES-A tarde } & Automóvel & 4 & 14,3 & 50,0 & 50,0 & 0,0 & 0,0 & 0,0 & 100 \\
\hline & $\begin{array}{l}\text { A pé e } \\
\text { bicicleta }\end{array}$ & 1 & 3,6 & 100,0 & 0,0 & 0,0 & 0,0 & 0,0 & 100 \\
\hline & Motocicleta & 1 & 3,6 & 100,0 & 0,0 & 0,0 & 0,0 & 0,0 & 100 \\
\hline & Ônibus e van & 22 & 78,6 & 4,5 & 27,3 & 4,5 & 27,3 & 36,4 & 100 \\
\hline & Total & 28 & 100 & & & & & & \\
\hline \multirow{5}{*}{ IES-A noite } & Automóvel & 103 & 29,3 & 51,5 & 37,9 & 8,7 & 1,0 & 1,0 & 100 \\
\hline & $\begin{array}{l}\text { A pé e } \\
\text { bicicleta }\end{array}$ & 2 & 0,6 & 50,0 & 50,0 & 0,0 & 0,0 & 0,0 & 100 \\
\hline & Motocicleta & 33 & 9,4 & 60,6 & 36,4 & 0,0 & 3,0 & 0,0 & 100 \\
\hline & Ônibus e van & 213 & 60,7 & 5,6 & 22,5 & 20,7 & 32,4 & 18,8 & 100 \\
\hline & Total & 351 & 100 & & & & & & \\
\hline \multirow{5}{*}{ IES-B noite } & Automóvel & 106 & 32,7 & 58,5 & 36,8 & 3,8 & 0,0 & 0,9 & 100 \\
\hline & $\begin{array}{l}\text { A pé e } \\
\text { bicicleta }\end{array}$ & 2 & 0,6 & 50,0 & 50,0 & 0,0 & 0,0 & 0,0 & 100 \\
\hline & Motocicleta & 70 & 21,6 & 54,3 & 38,6 & 7,1 & 0,0 & 0,0 & 100 \\
\hline & Ônibus e van & 146 & 45,1 & 9,6 & 24,0 & 28,8 & 17,1 & 20,5 & 100 \\
\hline & Total & 324 & 100 & & & & & & \\
\hline \multirow{5}{*}{$\begin{array}{l}\text { IES-C } \\
\text { manhã }\end{array}$} & Automóvel & 19 & 82,6 & 84,2 & 15,8 & 0,0 & 0,0 & 0,0 & 100 \\
\hline & $\begin{array}{c}\text { A pé e } \\
\text { bicicleta }\end{array}$ & 0 & 0,0 & 0,0 & 0,0 & 0,0 & 0,0 & 0,0 & 100 \\
\hline & Motocicleta & 1 & 4,3 & 0,0 & 100,0 & 0,0 & 0,0 & 0,0 & 100 \\
\hline & Ônibus e van & 3 & 13,0 & 0,0 & 0,0 & 66,7 & 33,3 & 0,0 & 100 \\
\hline & Total & 23 & 100 & & & & & & \\
\hline \multirow{5}{*}{ IES-C noite } & Automóvel & 141 & 39,2 & 53,2 & 43,3 & 3,5 & 0,0 & 0,0 & 100 \\
\hline & $\begin{array}{l}\text { A pé e } \\
\text { bicicleta }\end{array}$ & 0 & 0,0 & 0,0 & 0,0 & 0,0 & 0,0 & 0,0 & 100 \\
\hline & Motocicleta & 83 & 23,1 & 44,6 & 51,8 & 1,2 & 0,0 & 2,4 & 100 \\
\hline & Ônibus e van & 136 & 37,8 & 3,7 & 31,6 & 17,6 & 18,4 & 28,7 & 100 \\
\hline & Total & 360 & 100 & & & & & & \\
\hline \multirow{5}{*}{$\begin{array}{l}\text { IES-D } \\
\text { manhã }\end{array}$} & Automóvel & 20 & 40,0 & 75,0 & 25,0 & 0,0 & 0,0 & 0,0 & 100 \\
\hline & $\begin{array}{c}\text { A pé e } \\
\text { bicicleta }\end{array}$ & 8 & 16,0 & 50,0 & 50,0 & 0,0 & 0,0 & 0,0 & 100 \\
\hline & Motocicleta & 5 & 10,0 & 80,0 & 20,0 & 0,0 & 0,0 & 0,0 & 100 \\
\hline & Ônibus e van & 17 & 34,0 & 0,0 & 35,3 & 29,4 & 29,4 & 5,9 & 100 \\
\hline & Total & 50 & 100 & & & & & & \\
\hline \multirow{5}{*}{ IES-D noite } & Automóvel & 79 & 38,2 & 44,3 & 53,2 & 2,5 & 0,0 & 0,0 & 100 \\
\hline & $\begin{array}{l}\text { A pé e } \\
\text { bicicleta }\end{array}$ & 20 & 9,7 & 60,0 & 40,0 & 0,0 & 0,0 & 0,0 & 100 \\
\hline & Motocicleta & 18 & 8,7 & 61,1 & 38,9 & 0,0 & 0,0 & 0,0 & 100 \\
\hline & Ônibus e van & 90 & 43,5 & 13,3 & 41,1 & 18,9 & 15,6 & 11,1 & 100 \\
\hline & Total & 207 & 100 & & & & & & \\
\hline
\end{tabular}

* Valores médios diários das viagens atraídas. As viagens ocorridas aos sábados não foram contabilizadas por serem de pequena quantidade em relação aos demais dias da semana. 
Verifica-se, na Tabela 12, para o modo de transporte automóvel, que o tempo gasto para os alunos chegarem às instituições é de menos de 30 minutos, em sua maioria. Merece destaque os resultados obtidos nas IES-C e IES-D, turno da manhã, onde 84,2\% e 75,0\%, respectivamente, gastam menos de 15 minutos.

Quanto ao modo de transporte a pé e bicicleta nota-se, assim como para o modo de transporte automóvel, que o tempo gasto nas viagens atraídas é de menos de 30 minutos para a grande maioria dos usuários. Contudo, é importante ressaltar que para o modo a pé e bicicleta, poucos usuários utilizam a bicicleta. Como exemplo cita-se a IES-D turno da noite, onde 20 usuários se enquadraram na categoria a pé e bicicleta, contudo, apenas dois utilizaram a bicicleta para se locomoverem até à instituição de ensino. Apesar disso, a IES-D, de uma maneira geral, apresentou os maiores valores de respondentes que optaram por esse modo de transporte. Essa condição pode ser explicada pela localização da instituição de ensino, a qual está inserida em uma zona mista (Zona Central), onde existem casas e comércios no entorno, o que contribui para um menor deslocamento dos usuários, entre sua casa/trabalho e a instituição.

Quanto ao modo de transporte motocicleta verifica-se, na Tabela 12, que grande maioria dos usuários gasta menos de 30 minutos para chegar à instituição. Quando se analisa o modo de transporte ônibus e van constata-se uma grande distribuição dos percentuais do tempo de viagem. Nota-se semelhança no tempo de viagem entre os usuários das IES-A e IES-D turno da manhã e IES-C e IES-D turno da noite. Em uma análise específica da IES-C turno da manhã nota-se que o tempo de viagem para o modo de transporte ônibus e van situa-se entre 31 e 60 minutos, com a grande maioria dos usuários (66,7\%) gastando de 31 a 45 minutos no trajeto entre a residência e a escola.

Quanto às viagens produzidas, Tabela 13, verifica-se, para o modo de transporte automóvel, que o tempo gasto para os alunos chegarem às instituições é de menos de 30 minutos, em sua maioria. Assim como observado nas viagens atraídas, os resultados obtidos nas IES-C e IESD turno da manhã se sobressaíram em relação aos demais modos de transporte, com valores percentuais, para um tempo de viagem de menos de 15 minutos, de 78,9\% e 64,7\%, respectivamente. 
Tabela 13 - Tempo gasto pelos alunos nas viagens produzidas para os principais modos de transporte

\begin{tabular}{|c|c|c|c|c|c|c|c|c|c|}
\hline \multirow[t]{2}{*}{ Instituição } & \multirow{2}{*}{$\begin{array}{c}\text { Modo de } \\
\text { Transporte }\end{array}$} & \multicolumn{2}{|c|}{$\begin{array}{c}\text { Viagens } \\
\text { Produzidas* }\end{array}$} & \multicolumn{6}{|c|}{$\begin{array}{l}\text { Percentuais do tempo de viagem em função do modo } \\
\text { de transporte }(\%)\end{array}$} \\
\hline & & Número & $(\%)$ & $<15$ & 15 a 30 & 31 a 45 & 46 a 60 & $>60$ & Total \\
\hline \multirow{5}{*}{$\begin{array}{l}\text { IES-A } \\
\text { manhã }\end{array}$} & Automóvel & 44 & 37,6 & 52,3 & 43,2 & 4,5 & 0,0 & 0,0 & 100 \\
\hline & $\begin{array}{l}\text { A pé e } \\
\text { bicicleta }\end{array}$ & 2 & 1,7 & 50,0 & 50,0 & 0,0 & 0,0 & 0,0 & 100 \\
\hline & Motocicleta & 5 & 4,3 & 20,0 & 80,0 & 0,0 & 0,0 & 0,0 & 100 \\
\hline & Ônibus e van & 66 & 56,4 & 9,1 & 34,8 & 28,8 & 15,2 & 12,1 & 100 \\
\hline & Total & 117 & 100 & & & & & & \\
\hline \multirow{5}{*}{ IES-A tarde } & Automóvel & 21 & 30,0 & 57,1 & 38,1 & 4,8 & 0,0 & 0,0 & 100 \\
\hline & $\begin{array}{l}\text { A pé e } \\
\text { bicicleta }\end{array}$ & 3 & 4,3 & 100,0 & 0,0 & 0,0 & 0,0 & 0,0 & 100 \\
\hline & Motocicleta & 3 & 4,3 & 66,7 & 33,3 & 0,0 & 0,0 & 0,0 & 100 \\
\hline & Ônibus e van & 43 & 61,4 & 4,7 & 32,6 & 30,2 & 20,9 & 11,6 & 100 \\
\hline & Total & 70 & 100 & & & & & & \\
\hline \multirow{5}{*}{ IES-A noite } & Automóvel & 121 & 31,7 & 41,3 & 52,9 & 5,0 & 0,0 & 0,8 & 100 \\
\hline & $\begin{array}{l}\text { A pé e } \\
\text { bicicleta }\end{array}$ & 3 & 0,8 & 66,7 & 33,3 & 0,0 & 0,0 & 0,0 & 100 \\
\hline & Motocicleta & 32 & 8,4 & 53,1 & 43,8 & 0,0 & 0,0 & 3,1 & 100 \\
\hline & Ônibus e van & 226 & 59,2 & 3,1 & 19,5 & 24,3 & 27,0 & 26,1 & 100 \\
\hline & Total & 382 & 100 & & & & & & \\
\hline \multirow{5}{*}{ IES-B noite } & Automóvel & 108 & 33,1 & 57,4 & 38,9 & 2,8 & 0,0 & 0,9 & 100 \\
\hline & $\begin{array}{l}\text { A pé e } \\
\text { bicicleta }\end{array}$ & 2 & 0,6 & 50,0 & 50,0 & 0,0 & 0,0 & 0,0 & 100 \\
\hline & Motocicleta & 70 & 21,5 & 52,9 & 40,0 & 7,1 & 0,0 & 0,0 & 100 \\
\hline & Ônibus e van & 146 & 44,8 & 8,2 & 24,7 & 21,9 & 19,9 & 25,3 & 100 \\
\hline & Total & 326 & 100 & & & & & & \\
\hline \multirow{5}{*}{$\begin{array}{l}\text { IES-C } \\
\text { manhã }\end{array}$} & Automóvel & 19 & 82,6 & 78,9 & 15,8 & 5,3 & 0,0 & 0,0 & 100 \\
\hline & $\begin{array}{l}\text { A pé e } \\
\text { bicicleta }\end{array}$ & 0 & 0,0 & 0,0 & 0,0 & 0,0 & 0,0 & 0,0 & 100 \\
\hline & Motocicleta & 1 & 4,3 & 0,0 & 100,0 & 0,0 & 0,0 & 0,0 & 100 \\
\hline & Ônibus e van & 3 & 13,0 & 0,0 & 0,0 & 66,7 & 33,3 & 0,0 & 100 \\
\hline & Total & 23 & 100 & & & & & & \\
\hline \multirow{5}{*}{ IES-C noite } & Automóvel & 149 & 41,0 & 61,7 & 35,6 & 2,7 & 0,0 & 0,0 & 100 \\
\hline & $\begin{array}{l}\text { A pé e } \\
\text { bicicleta }\end{array}$ & 0 & 0,0 & 0,0 & 0,0 & 0,0 & 0,0 & 0,0 & 100 \\
\hline & Motocicleta & 85 & 23,4 & 56,5 & 41,2 & 1,2 & 0,0 & 1,2 & 100 \\
\hline & Ônibus e van & 129 & 35,5 & 5,4 & 24,0 & 17,8 & 20,2 & 32,6 & 100 \\
\hline & Total & 363 & 100 & & & & & & \\
\hline \multirow{5}{*}{$\begin{array}{l}\text { IES-D } \\
\text { manhã }\end{array}$} & Automóvel & 17 & 34,0 & 64,7 & 29,4 & 5,9 & 0,0 & 0,0 & 100 \\
\hline & $\begin{array}{c}\text { A pé e } \\
\text { bicicleta }\end{array}$ & 7 & 14,0 & 85,7 & 14,3 & 0,0 & 0,0 & 0,0 & 100 \\
\hline & Motocicleta & 5 & 10,0 & 40,0 & 60,0 & 0,0 & 0,0 & 0,0 & 100 \\
\hline & Ônibus e van & 21 & 42,0 & 9,5 & 38,1 & 19,0 & 23,8 & 9,5 & 100 \\
\hline & Total & 50 & 100 & & & & & & \\
\hline \multirow{5}{*}{ IES-D noite } & Automóvel & 93 & 44,3 & 51,6 & 47,3 & 1,1 & 0,0 & 0,0 & 100 \\
\hline & $\begin{array}{l}\text { A pé e } \\
\text { bicicleta }\end{array}$ & 11 & 5,2 & 63,6 & 36,4 & 0,0 & 0,0 & 0,0 & 100 \\
\hline & Motocicleta & 18 & 8,6 & 44,4 & 55,6 & 0,0 & 0,0 & 0,0 & 100 \\
\hline & Ônibus e van & 88 & 41,9 & 3,4 & 37,5 & 19,3 & 18,2 & 21,6 & 100 \\
\hline & Total & 210 & 100 & & & & & & \\
\hline
\end{tabular}

* Valores médios diários das viagens produzidas. As viagens ocorridas aos sábados não foram contabilizadas por serem de pequena monta em relação aos demais dias da semana. 
Para ao modo de transporte a pé e bicicleta observa-se que a maioria dos usuários gasta menos de 30 minutos, no trajeto entre a instituição de ensino e o seu local de destino. Para o modo de transporte motocicleta nota-se que a maioria dos usuários gasta, nas viagens produzidas, menos de 30 minutos. Especificamente na IES-B e IES-C turno da noite (Tabela 13) há uma grande quantidade de usuários que utilizam esse modo de transporte.

Quando se analisa o modo de transporte ônibus e van constata-se uma grande variação no tempo de viagem, tanto para as viagens atraídas quanto para as produzidas.

Estudos voltados à caracterização do padrão de viagens de instituições de ensino superior são importantes para fornecer dados para a definição de ações voltadas à minimização de problemas como congestionamentos, demanda por estacionamento, alterações nos padrões de uso e ocupação do solo, poluição ambiental, entre outros, apresentados com a implantação desses empreendimentos. Nesse sentido, os resultados gerados neste capítulo poderão auxiliar os administradores municipais no planejamento e, consequentemente, na minimização de problemas dessa ordem, verificados em cidades de porte médio como a cidade de Uberlândia.

\section{Conclusão}

Os estudos relacionados com a caracterização do padrão de viagens, em instituições de ensino superior, enquanto Polos Geradores de Viagens são escassos na literatura brasileira. Nesse sentido, este trabalho apresenta contribuições importantes.

Observou-se uma constância no número de viagens atraídas ao longo da semana somente para o turno noturno. Para os demais turnos notou-se que a sexta-feira apresentou uma menor quantidade de viagens quando comparada com os demais dias da semana, tanto para o turno da manhã quanto para a tarde. Foi observado para o turno da manhã, que as taxas de viagens atraídas foram maiores do que as de viagens produzidas. Para os demais turnos, tarde e noite, as viagens produzidas apresentaram taxas maiores do que as das atraídas.

A análise do modo de transporte mostrou que, tanto para as viagens atraídas quanto para as produzidas, o principal modo de transporte utilizado pelos alunos foi o ônibus e a van. A IESC foi a única instituição, dentre as quatro pesquisadas, onde se verificou que o principal modo de transporte foi o automóvel, tanto para as viagens atraídas como para as produzidas. Podese concluir que o transporte público urbano e o interurbano têm muito a melhorar na sua 
oferta e qualidade. Atualmente, o transporte por ônibus é utilizado devido a não possibilidade de os usuários adquirirem um automóvel, como ficou demonstrado na pesquisa a preferência por esse meio.

Quanto ao local de origem e destino das viagens concluiu-se que o perfil dos alunos que estudam durante o dia é diferente dos que estudam no período noturno. Uma minoria dos alunos que estudam durante o dia trabalha, sendo assim, a origem das viagens tem predominância na residência. Contudo, o destino dessas viagens é heterogêneo, principalmente no período da manhã, onde alguns alunos saem da instituição e vão diretamente para o trabalho ou estágio. Para o turno noturno, boa parte dos alunos trabalha ou faz estágio durante o dia. Para esse turno, conclui-se que o total das viagens que partem da instituição tem a residência como destino.

Para a localização física da origem e destino das viagens conclui-se que as viagens para as IES-A e B têm origem e destino, predominantemente, em bairros localizados no setor Leste da cidade. Conclui-se, também, que as viagens que chegam à IES-C têm origem em bairros dos setores Leste, Oeste e Sul. As viagens que partem dessa instituição têm como destino, em sua maioria, bairros localizados nos setores Leste e Sul. Por fim, o local de origem e destino das viagens realizadas pelos alunos da IES-D tem predominância em bairros do setor Oeste.

Para os modos de transporte a pé e bicicleta, automóvel e motocicleta o tempo gasto nas viagens atraídas e produzidas é de menos de 15 minutos, para a grande maioria dos usuários. Para o modo de transporte ônibus e van verificou-se que o tempo de viagem apresentou grande variação, tanto para as viagens atraídas quanto para as produzidas, e, portanto, pode-se concluir que todos os usuários que utilizam esse modo de transporte gastam mais de 30 minutos nos seus trajetos de ida e volta à instituição.

\section{Agradecimentos}

Os autores agradecem a Fundação de Amparo à Pesquisa de Minas Gerais - FAPEMIG, pela concessão da bolsa de pesquisa, nível Mestrado, à primeira autora. Esta pesquisa contou com o apoio financeiro da RedPGV. 


\section{Referências}

Andrade, E. P. (2005) Análise de métodos de estimativa de produção de viagens em polos geradores de tráfego. Dissertação de Mestrado. Universidade Federal do Rio de Janeiro, Rio de Janeiro.

Ary, M. B. (2002) Análise da demanda de viagens atraídas por shopping centers em Fortaleza. Dissertação de Mestrado. Universidade Federal do Ceará, Fortaleza.

Barbetta, P. A. (2004) Estatística aplicada às ciências sociais. Florianópolis: Editora UFSC.

Bertazzo, A. B. S. (2008) Estimativa e avaliação do padrão de viagens geradas para instituições de ensino médio. Dissertação de Mestrado. Universidade de Brasília, Brasília.

Instituto Nacional de Estudos e Pesquisas Educacionais Anísio Teixeira - INEP (2009) Estatísticas da Educação Superior. Disponível em www.inep.gov.br.

Institute of Transportation Engineers - ITE (2001) Trip Generation Handbook. Washington: Editora ITE.

Jacques, M. A. P., Bertazzo, A., Calarraga, J. e Herz, M. (2010) Nova abordagem para o estudo das viagens geradas nas instituições de ensino. Transportes, vol. 18, n. 1, pp. 75-85.

Ministério da Educação - MEC (2012) Sistema e-MEC. Texto não publicado. Disponível em: emec.mec.gov.br.

Nunes, J. L. (2005) Estudo da demanda por estacionamento em Instituições de Ensino Superior. Dissertação de Mestrado. Universidade de Brasília, Brasília.

Portugal, L. S. e Goldner, L. G. (2003) Estudo de polos geradores de tráfego e de seus impactos nos sistemas viários e de transportes. São Paulo: Editora Edgard Blücher.

Rosa, T. F. A. (2003) Variáveis sócio-econômicas na geração de viagens para shopping centers. Dissertação de Mestrado. Instituto Militar de Engenharia, Rio de Janeiro.

Souza, S. C. F. (2007) Modelos para estimativa de viagens geradas por Instituições de Ensino Superior. Dissertação de Mestrado. Universidade de Brasília, Brasília.

Uberlândia (2012) Bairros Integrados. Texto não publicado. Disponível em www.uberlandia.mg.gov.br. 